\title{
Spectroscopic studies of molecular iodine emitted into the gas phase by seaweed
}

\author{
S. M. Ball ${ }^{1}$, A. M. Hollingsworth ${ }^{1}$, J. Humbles ${ }^{1}$, C. Leblanc ${ }^{2}$, P. Potin ${ }^{2}$, and G. McFiggans ${ }^{3}$ \\ ${ }^{1}$ Department of Chemistry, University of Leicester, Leicester, LE1 7RH, UK \\ ${ }^{2}$ Station Biologique, Université Pierre et Marie Curie - Paris 6 CNRS UMR7139, Roscoff, France \\ ${ }^{3}$ Centre for Atmospheric Sciences, School of Earth, Atmospheric and Environmental Sciences, University of Manchester, \\ Manchester, M13 9PL, UK
}

Received: 3 November 2009 - Published in Atmos. Chem. Phys. Discuss.: 10 December 2009

Revised: 26 April 2010 - Accepted: 23 June 2010 - Published: 9 July 2010

\begin{abstract}
Time profiles of molecular iodine emissions from seven species of seaweed have been measured at high time resolution $(7.5 \mathrm{~s})$ by direct spectroscopic quantification of the gas phase $\mathrm{I}_{2}$ using broadband cavity enhanced absorption spectroscopy. Substantial differences were found between species, both in the amounts of $I_{2}$ emitted when the plants were exposed to air and in the shapes of their emission time profiles. Two species of kelp, Laminaria digitata and Laminaria hyperborea, were found to be the most potent emitters, producing an intense burst of $I_{2}$ when first exposed to air. $\mathrm{I}_{2}$ was also observed from Saccharina latissima and Ascophyllum nodosum but in lower amounts and with broader time profiles. $\mathrm{I}_{2}$ mixing ratios from two Fucus species and Dictyopteris membranacea were at or below the detection limit of the present instrument ( $25 \mathrm{pptv})$. A further set of experiments investigated the time dependence of $\mathrm{I}_{2}$ emissions and aerosol particle formation when fragments of $L$. digitata were exposed to desiccation in air, to ozone and to oligoguluronate stress factors. Particle formation occurred in all $L$. digitata stress experiments where ozone and light were present, subject to the $I_{2}$ mixing ratios being above certain threshold amounts. Moreover, the particle number concentrations closely tracked variations in the $\mathrm{I}_{2}$ mixing ratios, confirming the results of previous studies that the condensable particle-forming gases derive from the photochemical oxidation of the plant's $\mathrm{I}_{2}$ emissions. This work also supports the theory that particle nucleation in the coastal atmosphere occurs in "hot-spot" regions of locally elevated concentrations of condensable gases: the greatest atmospheric concentrations of $I_{2}$ and hence of condensable iodine oxides are likely to be above plants of the most efficiently emitting kelp species and localised in time to shortly after these seaweeds are uncovered by a receding tide.
\end{abstract}

Correspondence to: $\mathrm{S}$. Ball

(sb263@leicester.ac.uk)

\section{Introduction}

The rapid nucleation of large numbers of ultra-fine aerosol particles has been reported from several field studies conducted at Mace Head on the west coast of Ireland (O'Dowd et al., 2002; O'Dowd and Hoffmann, 2005; Saiz-Lopez et al., 2006). A similar phenomenon was also recently observed during the Reactive Halogens in the Marine Boundary Layer (RHaMBLe) field campaign at Roscoff on the north Brittany coast of France (Whitehead et al., 2009; McFiggans et al., 2010). These nucleation events tend to occur in "bursts" around daytime low tides (but not generally night-time low tides), the most intense events occurring on days with the lowest tides. A fraction of these newly nucleated particles may subsequently grow large enough to act as cloud condensation nuclei $(\mathrm{CCN})$ and hence affect cloud properties and lifetimes, potentially also changing the radiative forcing in coastal regions (see McFiggans et al., 2006, and references therein for a discussion of the properties impacting on aerosol behaviour as $\mathrm{CCN}$ ).

Parallel studies conducted in laboratory chambers and flow reactors have observed particle formation following the gas phase photo-oxidation of $\mathrm{CH}_{2} \mathrm{I}_{2}$ (Jimenez et al., 2003) and the head-space gases sampled from above one particular species of kelp seaweed, Laminaria digitata (McFiggans et al., 2004). Indeed, the particles formed from $L$. digitata exposure were found to have the same composition (iodine oxides), morphology and hydroscopic behaviour as particles formed from $\mathrm{CH}_{2} \mathrm{I}_{2}$. Together, the laboratory and field observations have lead investigators to conclude that particle nucleation in coastal areas follows from the in situ photochemical production of highly condensable iodine oxides derived from iodine-containing precursor gases emitted into the atmosphere by seaweed beds exposed around low tide. Since the McFiggans et al. (2004) publication, further flow reactor studies have confirmed that both halocarbons and molecular

Published by Copernicus Publications on behalf of the European Geosciences Union. 
iodine are emitted into the gas phase when $L$. digitata is exposed to oxidative stresses e.g. ozone, $\mathrm{H}_{2} \mathrm{O}_{2}$ or oligoguluronates (Palmer et al., 2005; Küpper et al., 2008), with particle formation observed in the presence of ozone. $\mathrm{I}_{2}$ emissions have also been seen in studies where the seaweed samples were merely exposed to ambient air (i.e. without applying any additional stress): $\mathrm{I}_{2}$ emission was observed from L. digitata by Dixneuf et al. (2009) and Bale et al. (2008), and both $\mathrm{I}_{2}$ emissions and particle nucleation were observed by Sellegri et al. (2005) from "Laminaria and Fucus" samples collected from around Mace Head.

Although the nucleation kinetics have yet to be understood in detail and significant uncertainties remain about the photochemistry and reaction rate coefficients for some of the gas phase species, it is generally accepted that particle formation proceeds as follows:

Iodocarbons, $\mathrm{I}_{2} \rightarrow$ I atoms $\rightarrow$ IO $\rightarrow$ OIO

$\rightarrow \mathrm{I}_{2} \mathrm{O}_{\mathrm{y}}(\mathrm{y}=2$ to 5$) \rightarrow$ stable particle nuclei.

The sequence begins with certain species of seaweed such as L. digitata emitting iodocarbons and/or molecular iodine into the atmosphere in response to the stress of being exposed by an ebb tide. L. digitata is known to be a prodigious accumulator of iodine from sea water, capable of reaching more than $1 \%$ iodine by dry weight (Küpper et al., 1998; Ar Gall et al., 2004). The iodine is stored as the iodide anion, $\mathrm{I}^{-}$, partially solvated by water but with its hydration shell disrupted by hydrogen-bonding to organic biomolecules (Küpper et al., 2008). The greatest iodide concentrations are found in the plant's peripheral tissues from where it is released to react with reactive oxygen species (ROS: $\mathrm{H}_{2} \mathrm{O}_{2}, \mathrm{O}_{3}, \mathrm{O}_{2}^{-},{ }^{1} \mathrm{O}_{2}$, $\mathrm{HO}_{2}$ ) (Verhaeghe et al., 2008; Küpper et al., 2008). It seems that $I_{2}$ is not emitted directly by the seaweed, but rather is the product of chemistry that occurs outside the cell membrane when the plant acts to combat oxidative stresses. Thus $I_{2}$ is produced (i) by the reaction between, for example, gas phase ozone and $\mathrm{I}^{-}$when the plant's surface is exposed to the atmosphere at low tide (i.e. iodide acting as an inorganic antioxidant; Küpper et al., 2008), and (ii) by enzymatic reactions between aqueous phase $\mathrm{H}_{2} \mathrm{O}_{2}$ and $\mathrm{I}^{-}$in the apoplast catalysed by vanadium-dependent haloperoxidases and, in the case of kelp species, the more specialised iodoperoxidase enzymes (Colin et al., 2005; Küpper et al., 2008). Emission of halocarbons is also likely to be a by-product of haloperoxidase activity, and since iodocarbons have a high microbial toxicity, it is thought that they are involved in a chemical defence mechanism in kelp (Küpper et al., 2008).

Once released into the atmosphere, the iodine-containing source gases undergo photolysis by solar radiation with lifetimes ranging from under $10 \mathrm{~s}\left(\mathrm{I}_{2}\right)$, to several minutes (e.g. $\left.\mathrm{CH}_{2} \mathrm{I}_{2}\right)$, to a few days $\left(\mathrm{CH}_{3} \mathrm{I}\right)$. It was initially thought that $\mathrm{CH}_{2} \mathrm{I}_{2}$ was the main iodine-containing precursor leading to particle formation under atmospheric conditions (e.g. Jimenez et al., 2003). However, at least in coastal regions, it now seems more likely that molecular iodine provides the dominant iodine atom flux because $\mathrm{I}_{2}$ concentrations typically exceed those of $\mathrm{CH}_{2} \mathrm{I}_{2}$ and because $\mathrm{I}_{2}$ has a substantially shorter photolytic lifetime (McFiggans et al., 2004). The photochemically produced iodine atoms quickly react with ozone to give iodine monoxide radicals (IO). Iodine dioxide radicals $(\mathrm{OIO})$ are then produced as the dominant channel in the reaction between two IO radicals. OIO is thought to undergo its own self reaction to produce $\mathrm{I}_{2} \mathrm{O}_{4}$ and to react with IO to produce $\mathrm{I}_{2} \mathrm{O}_{3}$, both of which, if not already stable nuclei themselves, react with ozone to produce $\mathrm{I}_{2} \mathrm{O}_{5}$ and/or add further IO and OIO units to yield polymeric iodine oxides and ultimately newly nucleated aerosol particles (Burkholder et al., 2004; McFiggans et al., 2004; Pirjola et al., 2005; Kaltsoyannis and Plane, 2008). It is also probable that OIO co-condenses with other molecules such as $\mathrm{H}_{2} \mathrm{SO}_{4}$ or low volatility organic compounds (Vuollekoski et al., 2009).

Iodine chemistry also has important impacts on the trace gas composition of the marine boundary layer (von Glasow and Crutzen, 2007). Catalytic cycles driven primarily by the IO radical act to deplete tropospheric ozone and affect the oxidising capacity of the coastal atmosphere by perturbing the partitioning within the $\mathrm{NO}_{2} / \mathrm{NO}$ and $\mathrm{HO}_{2} / \mathrm{OH}$ radical families (Davis et al., 1996; Bloss et al., 2005; Mahajan et al., 2009). There have now been many observations of IO in the marine atmosphere by long path differential optical absorption spectroscopy (LP-DOAS) - see the tables summarising IO, OIO and $\mathrm{I}_{2}$ observations in Peters et al. (2005), von Glasow and Crutzen (2007), Seitz (2009) and Huang et al. (2010). IO was also detected by LP-DOAS during the RHaMBLe coastal deployment at Roscoff (Mahajan et al., 2009) and additionally by laser induced fluorescence (Whalley et al., 2007) and cavity ringdown spectroscopy (Wada et al., 2007). In contrast there have been far fewer direct spectroscopic observations of atmospheric IO's likely precursor, $I_{2}$, and the vast majority of these $I_{2}$ observations have been made around the Mace Head area (Saiz-Lopez and Plane, 2004; Bitter et al., 2005; Peters et al., 2005; Saiz-Lopez et al., 2006; Bloss and Ball, 2009; Seitz, 2009; Huang et al., 2010). Notably Peters et al. (2005) were unable to find any $\mathrm{I}_{2}$ above their detection limit of $\sim 20$ pptv during a campaign at Lilia, Brittany, even in the presence of strong iodocarbon and IO signals. And only recently have direct spectroscopic observations of $I_{2}$ been reported at locations other than Mace Head: $I_{2}$ has been detected at La Jolla, California, using chemical ionisation mass spectrometry (Finley and Saltzman, 2008) and at Roscoff using LP-DOAS (Mahajan et al., 2009) and broadband cavity ringdown spectroscopy (Leigh et al., 2009).

This work uses broadband cavity enhanced absorption spectroscopy (BBCEAS), a highly sensitive type of optical absorption spectroscopy, to quantify $\mathrm{I}_{2}$ concentrations in gas flows passed over seaweed samples exposed to desiccation in air and to other stress factors. The aim was to follow the time 
profiles of $I_{2}$ emissions from different seaweed species in order to understand which species contribute to atmospheric $I_{2}$ and explain why, for example, $\mathrm{I}_{2}$ has been known for several years at Mace Head but has only recently been observed at other coastal locations. Two distinct types of experiment were conducted at the Station Biologique de Roscoff (SBR) during the final week of the RHaMBLe coastal deployment in September 2006:

(i) Incubation experiments were performed on whole plants of 7 different seaweed species - here the aim was to monitor time-dependent $I_{2}$ emissions from seaweeds when first exposed to air, and thus to mimic what occurs in their natural environment around low tides.

(ii) Fragments of L. digitata thalli were variously exposed to air, ozone and oligoguluronate in order to monitor their stress response in terms of time-dependent $I_{2}$ emissions and how those emissions correlated with any subsequent aerosol particle formation.

BBCEAS spectra were recorded between 522 and $554 \mathrm{~nm}$ in a spectral region where the $\mathrm{I}_{2}$ molecule possesses characteristic and highly structured absorption bands. The detection limit of the present system for $\mathrm{I}_{2}$ is around 25 pptv (parts per trillion by volume; $10^{-12}$ mixing ratio) for an integration time of $7.5 \mathrm{~s}$, thus allowing the emission of even small quantities of $\mathrm{I}_{2}$ to be monitored at high time resolution. To our knowledge, the direct spectroscopic detection of $\mathrm{I}_{2}$ from seaweed has only previously been reported for $L$. digitata exposed to ambient air (Bale et al., 2008; Dixneuf et al., 2009). This work extends high time resolution observations of $I_{2}$ to other seaweed species and to L. digitata exposed to stress factors. Emission rates of $\mathrm{I}_{2}$ are also provided for both types of experiment.

\section{Method}

\subsection{Sample collection and preparation}

Thalli of Dictyopteris membranacea, Saccharina latissima, Laminaria digitata and Laminaria hyperborea were collected in the inter-tidal zone close to the Station Biologique de Roscoff (SBR) during the daytime low tide of 22 September 2006. The algae were stored in running sea water in the SBR aquarium, illuminated by natural light passing through the aquarium's many windows. When required for the incubation experiments, whole seaweed plants were removed from the aquarium's tanks, shaken free of excess water and placed in a ten litre, translucent, Nalgene plastic bottle. The bottle plus seaweed was weighed and then sealed with a screw cap. All experiments were conducted within 8 days of harvesting the samples. Ascophyllum nodosum, Fucus serratus and Fucus vesiculosus samples were taken directly from the beach outside the SBR within a few metres of the water's edge and were used immediately. The transit time from the aquarium/beach to beginning an experiment was around 3 min.

Some of the Laminaria digitata collected on 22 September was stored separately in one of the SBR's laboratories for use in the stress experiments on 27 and 28 September (running, aerated seawater at $9-17^{\circ} \mathrm{C}$; illuminated by a photon flux of 50-60 $\mu$ mol photons $\mathrm{m}^{-2} \mathrm{~s}^{-1}$ with a 12-h-on/12-h-off cycle). Fragments of thalli weighing between 5 and $10 \mathrm{~g}$ were cut before the start of each stress experiment, rinsed in seawater, and $\approx 20 \mathrm{~g}$ of sample was arranged around the walls of the small glass vessel (volume $\approx 200 \mathrm{~cm}^{3}$ ) that served to contain the seaweed in the flow reactor. The samples for stress experiments \#1, \#3 and \#4 were used immediately, whereas the sample for stress experiment \#2 comprised the same pieces of thalli used in experiment \#1 the previous evening and which had been allowed to recover in aerated seawater overnight. The thalli fragments for stress experiments \#3 and \#4 were additionally anointed with $10 \mathrm{~cm}^{3}$ of a solution of oligoguluronates $\left(150 \mu \mathrm{g} \mathrm{cm}^{-3}\right)$ for one minute and then rinsed with seawater before being placed in the flow reactor. Oligoguluronates (GG) are breakdown products of the algal cell wall and are recognised by the algae as an indicator of pathogen attack, provoking an oxidative stress response. The oligoguluronates were prepared by mild acid hydrolysis as previously described by Küpper et al. (2008) and Cosse et al. (2009). The four $L$. digitata stress experiments and all but two of the seaweed incubation experiments were performed in the SBR's cold room (air temperature $=12^{\circ} \mathrm{C}$ ): the two exceptions were the Dictyopteris membranacea and the first Laminaria hyperborea (healthy specimen) incubation experiments which were performed in a regular laboratory inside the SBR (ambient temperature $\approx 20^{\circ} \mathrm{C}$ ).

\subsection{Apparatus}

The upper panel of Fig. 1 shows a schematic of the apparatus used in the incubation experiments performed on whole seaweed plants. A mechanical pump forced ambient air $\left(2.81 \mathrm{~min}^{-1}\right)$ through an aerosol particle filter and along $\frac{1}{4}$ inch external diameter Teflon tubing that passed through a tube fitting in the screw cap of the Nalgene bottle containing the seaweed sample. A second Teflon tube conveyed gas out of the Nalgene bottle and into 1.5 inch diameter plastic tube enclosing the optical cavity of the BBCEAS instrument. Sample gas vented from the cavity through a small gap between the plastic tube and the cavity's mirror mounts.

The BBCEAS spectrometer was similar in form and function to an instrument previously used to quantify trace amounts of $\mathrm{NO}_{2}$ in the atmosphere (Langridge et al., 2006). The spectrometer's light source was a high intensity light emitting diode (Luxeon 3 Watt green LED, peak wavelength $=535 \mathrm{~nm}$ ) mounted on a fan-cooled heat sink. Light from the LED was coupled into a fibre optic cable abutted up against the emitter's surface and re-collimated at the far end of the fibre by a microscope objective lens. Two turning 
mirrors then directed the light beam into the optical cavity formed by two highly reflective mirrors (Layertec $\mathrm{GmbH}$ ). Light transmitted through the cavity's output mirror was collected by an $f=25 \mathrm{~mm}$ lens, focussed into a fibre optic cable, and dispersed and detected as a function of wavelength by a fibre-coupled spectrometer (OceanOptics HR4000) interfaced to a laptop computer.

The lower panel of Fig. 1 shows a schematic of the flow reactor used in the $L$. digitata stress experiments. A mechanical pump forced ambient air $\left(4.81 \mathrm{~min}^{-1}\right)$ sequentially through molecular sieve and charcoal traps to scrub the air free from ambient ozone and any volatile organic compounds (VOCs) that might otherwise be oxidised to particle-forming oxygenated-VOCs in the ozoniser. The flow then divided through two metering values, one line feeding an ozoniser (Penray ozone generator 97-0067-02 with mercury lamp) and water bubbler and the other line feeding a bubbler directly. Any aerosol formed by bubble bursting was removed by particle filters. The flows recombined, passed through the vessel containing the seaweed and flowed into a second larger glass vessel (residence time $\approx 20 \mathrm{~s}$ ). The purpose of this second vessel was to allow time for newly nucleated particles to grow by the further addition of condensable gases and thus reach a detectable size. The outflow from the aerosol growth vessel was divided three ways between a condensation particle counter (CPC; TSI model 3776, size cut-off $\mathrm{D}_{P}=3 \mathrm{~nm}$ ), an ozone monitor (2B Technologies model 202) and a line supplying gas to the BBCEAS cavity. The net flow into the cavity was $3.31 \mathrm{~min}^{-1}$.

\subsection{Quantification of $I_{2}$ by BBCEAS}

The wavelength dependent absorption coefficient of the gas sample - hereafter termed the sample's BBCEAS spectrum - is given by the equation (Langridge et al., 2006; Ball and Jones, 2009):

$\alpha(\lambda)=\left(\frac{I_{0}(\lambda)}{I(\lambda)}-1\right) \times \frac{1-R(\lambda)}{d}$

where $I(\lambda)$ is the light intensity transmitted through the cavity when an absorbing gas sample is present within the cavity and $I_{0}(\lambda)$ is the intensity transmitted when the cavity is flushed with an non-absorbing gas, in this case pure nitrogen (Alphagas $\mathrm{N}_{2}$, Air Liquide). The remaining parameters in Eq. (1) are cavity's length, $d=116 \mathrm{~cm}$, and the wavelength dependent reflectivity of the mirrors, $R(\lambda)$. The HR4000 spectrometer recorded spectra of the transmitted light intensity with an integration time of $0.75 \mathrm{~s}$, and ten such acquisitions were averaged together to produce each $I(\lambda)$ or $I_{0}(\lambda)$ measurement before being saved to the laptop (i.e. a net acquisition time of $7.5 \mathrm{~s}$ ). In order to minimise noise when calculating the BBCEAS spectra, an averaged $I_{0}(\lambda)$ spectrum was constructed for each experiment from between thirty and fifty $7.5 \mathrm{~s}$ transmission spectra obtained when flushing the cavity with nitrogen, either prior to or after sampling gas
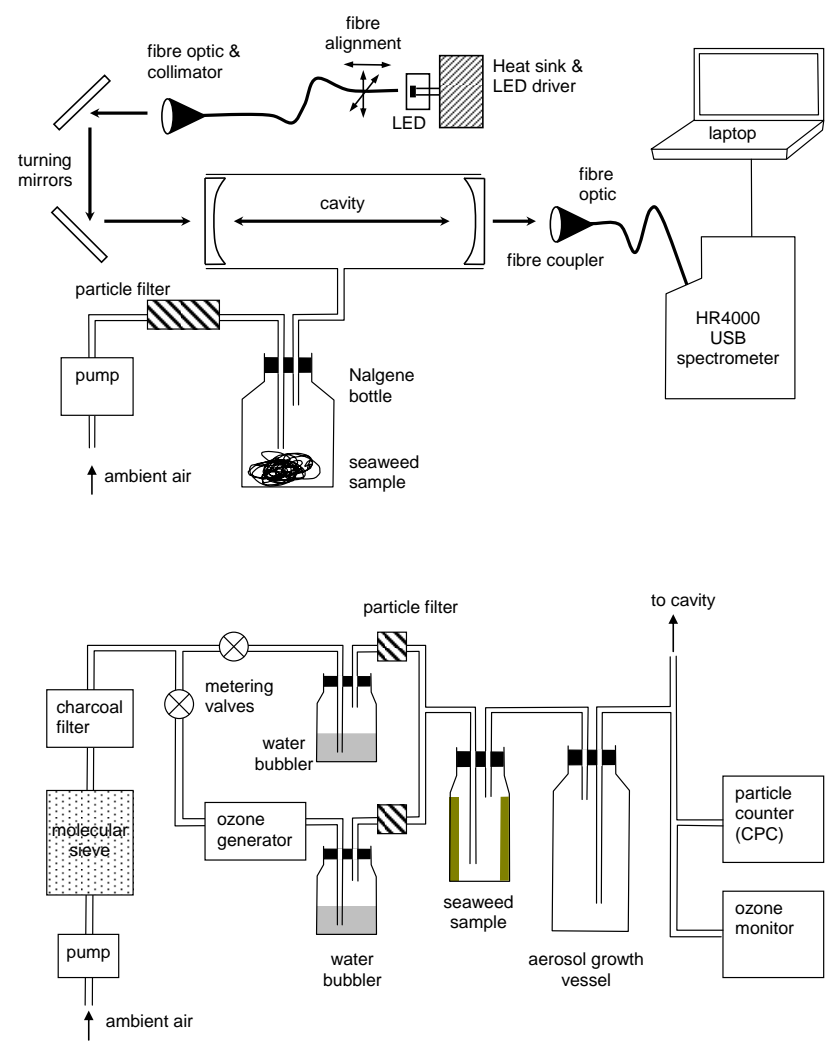

Fig. 1. Schematic diagrams of the apparatus and the BBCEAS spectrometer used in the seaweed incubation experiments (upper panel) and the flow reactor used in the Laminaria digitata stress experiments (lower panel).

from the seaweed container. BBCEAS spectra were then calculated for each $I(\lambda)$ spectrum (i.e. at a time resolution of $7.5 \mathrm{~s})$ using the averaged $I_{0}(\lambda)$ spectrum in Eq. (1).

The form of Eq. (1) shows that it is vital to know how the cavity mirror reflectivity varies with wavelength if BBCEAS is to be used to make quantitative measurements of trace gas concentrations (Ball and Jones, 2009). A convenient method for deriving $R(\lambda)$ is to record the BBCEAS spectrum of a sample of known composition and thus known $\alpha(\lambda)$. Here we adopt the approach of Langridge et al. (2006): $R(\lambda)$ was determined by flushing the cavity with pure oxygen and recording BBCEAS spectra of the collision-induced ${ }^{1} \Delta_{g}+{ }^{1} \Delta_{g}(v=2) \leftarrow{ }^{3} \Sigma_{g}^{-}+{ }^{3} \Sigma_{g}^{-}$absorption band of the $\mathrm{O}_{4}$ oxygen dimer around $532 \mathrm{~nm}$ (Greenblatt et al., 1990; Hermans, 2008). The precise form of the reflectivity versus wavelength curve obtained from fitting the $\mathrm{O}_{4}$ absorption feature was then adjusted to minimise the standard deviation of the residual spectrum when fitting (i) BBCEAS spectra of seaweed emissions containing very high iodine concentrations $\left(\left[\mathrm{I}_{2}\right]>10000 \mathrm{pptv}\right)$ on the assumption that their strong $\mathrm{I}_{2}$ absorption features overwhelmed all other possible absorbers, and (ii) BBCEAS spectra of $\mathrm{NO}_{2}$ diluted in nitrogen recorded after the Roscoff RHaMBLe campaign. Fitting 
the detailed differential spectral structure due to $\mathrm{I}_{2}$ and $\mathrm{NO}_{2}$ across the entire bandwidth of the present measurements produced subtle refinements in the shape of the $R(\lambda)$ curve, but did not reduce the quality of the fit to the oxygen dimer spectrum which remained the primary factor in determining $R(\lambda)$. The resultant mirror reflectivity curve had a broad, almost flat maximum of $R=99.955 \%$ at $525 \mathrm{~nm}$, decreasing smoothly to $R=99.912 \%$ at $554 \mathrm{~nm}$. Thus the enhancement factor of the cavity ranged from $1 /(1-R)=2230$ at $525 \mathrm{~nm}$ to 1140 at $554 \mathrm{~nm}$, corresponding to equivalent absorption paths through the intra-cavity sample of 2.59 and $1.33 \mathrm{~km}$, respectively.

A detailed discussion of how to retrieve absorber concentrations from spectra obtained with broadband cavity methods is given by Ball and Jones (2009). Briefly, BBCEAS spectra of gas mixtures usually contain structured features due to molecular absorbers and a broad, featureless absorption due to aerosol extinction and any other absorbers possessing unstructured absorptions over the wavelength range of the measurement. Differential optical absorption spectroscopy (DOAS) is applied to separate and individually quantify the structured contributions by fitting reference molecular absorption cross sections to the differential structure in the BBCEAS spectrum (e.g. Langridge et al., 2006, 2008; Ball and Jones, 2009). Three structured absorbers were included in the present analysis: $\mathrm{I}_{2}$ from the seaweed emissions, $\mathrm{H}_{2} \mathrm{O}$ from ambient humidity and an $\mathrm{O}_{4}$ contribution due to atmospheric oxygen (although in practice the weak and constant $\mathrm{O}_{4}$ contribution was subtracted from the BBCEAS spectrum prior to the DOAS fitting). An additional quadratic function represented the remaining unstructured absorption. Once its absorption coefficient had been retrieved by the DOAS analysis, the concentration of a given molecular absorber was obtained from the gradient of a plot of its absorption coefficent versus absorption cross section. Additionally, the $1 \sigma$ error in this gradient provided a measure of the statistical uncertainty associated with retrieving that absorber's concentration from the differential structure in the BBCEAS spectrum. This statistical fitting error was typically $\pm 20 \mathrm{pptv}$ for $\mathrm{I}_{2}$ mixing ratios around the detection limit, rising to $\approx 0.4 \%$ of the fitted amount for largest $\mathrm{I}_{2}$ signals in this study. Figure 2 shows examples of BBCEAS spectra measured during two of the seaweed incubation experiments, overlaid with the iodine absorption coefficients retrieved by the DOAS fitting routine. The $522-554 \mathrm{~nm}$ bandwidth of these spectra spans 18 vibrational bands of the $\mathrm{I}_{2}$ molecule's $\mathrm{B} \leftarrow \mathrm{X}$ electronic transition: this unique spectral signature provides unambiguous identification of $\mathrm{I}_{2}$ even at high dilution which, allied to the kilometre absorption path lengths achieved inside the cavity, gives the BBCEAS technique its very high sensitivity.
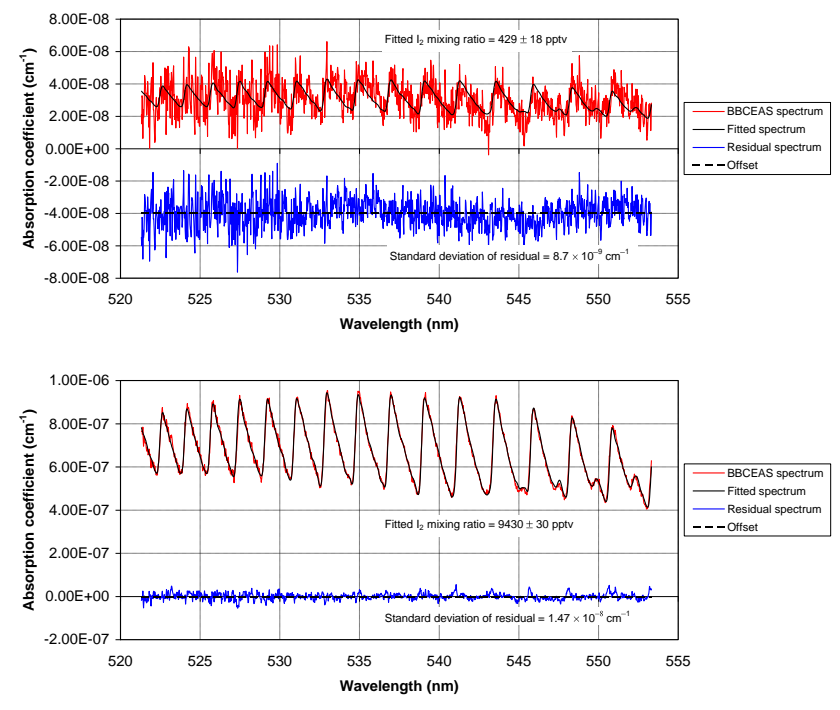

Fig. 2. Example BBCEAS spectra of $I_{2}$ emitted from Saccharina latissima (upper panel) and Laminaria digitata (lower panel). The measured BBCEAS spectrum is shown in red overlaid by the $\mathrm{I}_{2}$ absorption cross sections scaled to produce the optimum fit to the BBCEAS spectrum (black). The residual spectrum is shown in blue (measurement minus fitted spectrum), offset below zero by $4 \times 10^{-8} \mathrm{~cm}^{-1}$ for clarity in the upper panel. The BBCEAS spectra were obtained with an integration time of $7.5 \mathrm{~s}$. The uncertainties quoted for the retrieved $\mathrm{I}_{2}$ mixing ratios on this figure are the statistical errors in the $I_{2}$ amounts arising from fitting the molecule's differential structure in the BBCEAS spectrum.

\subsection{Choice of molecular absorption cross sections}

The $\mathrm{I}_{2}$ absorption cross sections used to fit the BBCEAS spectra were adapted from the values of Saiz-Lopez et al. (2004). Available on a wavelength grid of $\delta \lambda=0.1 \mathrm{~nm}$, the literature cross sections were still too coarse to fit the fine detail of the $\mathrm{I}_{2}$ differential structure in the present BBCEAS spectra. Instead $\mathrm{I}_{2}$ absorption spectra were calculated on a wavelength grid of $\delta \lambda=0.02 \mathrm{~nm}$ at the HR4000 spectrometer's resolution (Gaussian function $0.22 \mathrm{~nm}$ FWHM) using the $\mathrm{I}_{2}$ molecule's spectroscopic constants and the PGOPHER spectral simulation package (Martin et al., 1986; Western, 2009). Absorption cross sections were then obtained by applying a scaling constant to the simulated $\mathrm{I}_{2}$ spectrum such that its differential spectral structure best matched the differential structure in the Saiz-Lopez et al. (2004) cross sections over the 522-554 $\mathrm{nm}$ wavelength range. We estimate that the uncertainty in the simulated $\mathrm{I}_{2}$ cross sections is $15 \%$, compared to the $12 \%$ uncertainty quoted for the literature cross sections. Water vapour cross sections were calculated from the HITRAN 2004 spectral database (Rothman et al., 2005) and degraded to the spectrometer's resolution. At the present green wavelengths, it was not found necessary to include the possibility of water absorption lines becoming partially saturated over the effective path lengths encountered inside our 
BBCEAS cavity (cf. Langridge et al., 2008). The higher resolution $\mathrm{O}_{4}$ cross sections of Hermans (2008) were preferred over those of Greenblatt et al. (1990). However no information is provided about the uncertainty of the Hermans cross sections, and we estimate an uncertainty of $\sim 5 \%$ in the differential cross sections of the $532 \mathrm{~nm} \mathrm{O}_{4}$ band by comparison with the cross sections of Greenblatt et al. (1990) and the cavity ringdown study of Sneep and Ubachs (2005). Since the reflectivity of the cavity mirrors was determined from BBCEAS spectra of this $\mathrm{O}_{4}$ dimer band, the uncertainty in the $\mathrm{O}_{4}$ cross sections translates directly into a systematic 5\% uncertainty in the cavity enhancement factor and thus an additional 5\% uncertainty in the mixing ratios of all absorbers retrieved from fitting the BBCEAS spectra.

\section{Results}

\subsection{Incubation studies on whole seaweed plants}

A total of ten incubation experiments were performed on seven different seaweed species during the period 2730 September 2006. The results of these incubation experiments are summarised in Table 1 , and $\mathrm{I}_{2}$ emission time profiles from five experiments are shown in Figs. 3 and 4. Repeat experiments using different samples of the same species were generally not possible owing to the time constrains of the RHaMBLe field campaign. However repeat experiments were performed for Saccharina latissima $(\times 3)$ and Laminaria hyperborea $(\times 2)$, in part because some of the samples showed signs of mechanical damage or decay (this is noted in Table 1). The initial air-exposure phase of the L. digitata stress experiment \#1 in Sect. 3.2 provides a second repeat for that species.

Figure 3 shows time series of $I_{2}$ mixing ratios observed from three seaweed species: Dictyopteris membranacea (Fig. 3a), Ascophyllum nodosom (Fig. 3b) and a young healthy plant of Saccharina latissima (Fig. 3c). Each data point represents the $I_{2}$ mixing ratio retrieved from fitting a single BBCEAS spectrum, and thus the emission profiles in Fig. 3 et seq. have a time resolution of $7.5 \mathrm{~s}$ (Note: the HR4000 spectrometer's software was configured to record $I(\lambda)$ spectra in batches of $10 \times 7.5 \mathrm{~s}$ acquisitions when initiated by the operator, rather than by continuous acquisition; hence the data points in time profile plots are clustered in batches of ten, with occasional short breaks). The red data points are the $I_{2}$ mixing ratios in gas that had previously flowed over the seaweed samples and the lighter coloured yellow data points are $I_{2}$ mixing ratios retrieved from fitting BBCEAS spectra recorded when the cavity was flushed with dry nitrogen. The latter spectra have the same $7.5 \mathrm{~s}$ acquisition time and were calculated using individual $I_{0}(\lambda)$ spectra instead of individual $I(\lambda)$ spectra in the denominator of Eq. (1). The error bars accompanying each data point combine both the statistical uncertainty (i.e. gradient error)
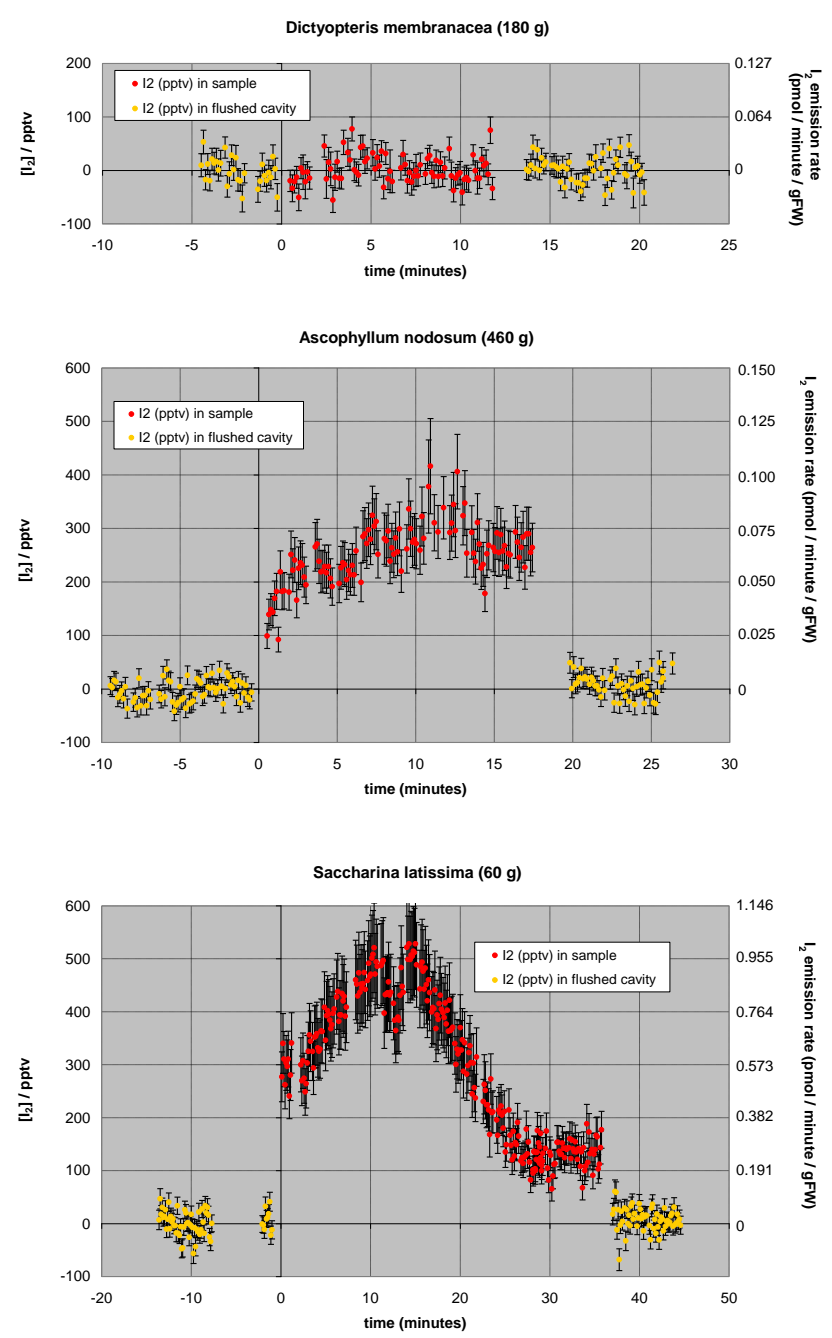

Fig. 3. Time series of the $I_{2}$ mixing ratios (left axis) and corresponding $\mathrm{I}_{2}$ emission rates (right axis) observed in the incubation experiments on Dictyopteris membranacea (top), Ascophyllum nodosum (middle) and a young, healthy Sacharrina latissima plant (bottom).

associated with retrieving the $\mathrm{I}_{2}$ mixing ratio and the systematic uncertainties in the $\mathrm{I}_{2}$ cross sections $(15 \%)$ and the cavity enhancement factor (5\%). The statistical fitting error dominates for $\mathrm{I}_{2}$ mixing ratios around/below the detection limit (e.g. Fig. 3a and all flushed cavity data points), whereas the systematic errors begin to dominate for $\mathrm{I}_{2}$ mixing ratios above a few hundred pptv (e.g. sample data points in Fig. 3b and c).

The time series in Fig. $3 \mathrm{~b}$ and $\mathrm{c}$ shows that the A. nodosom and $S$. latissima samples produced gas phase $\mathrm{I}_{2}$ at mixing ratios of several hundred parts per trillion by volume. Characteristic absorption bands of $I_{2}$ were clearly visible in the BBCEAS spectra confirming the presence of $\mathrm{I}_{2}$ : for example, the BBCEAS spectrum in the upper panel of Fig. 2 corresponds to one of the red data points in the 
Table 1. Iodine mixing ratios, emission profiles and emission rates observed during air exposure experiments performed on whole seaweed plants.

\begin{tabular}{|c|c|c|c|c|c|c|c|c|}
\hline \multirow[t]{2}{*}{ Species } & \multirow{2}{*}{$\begin{array}{l}\text { Fresh } \\
\text { weight } \\
(\mathrm{g})\end{array}$} & \multirow[t]{2}{*}{$\begin{array}{l}\text { Duration } \\
\text { (min) }\end{array}$} & \multirow[t]{2}{*}{$\mathrm{I}_{2}$ emission profile } & \multicolumn{3}{|c|}{$\mathrm{I}_{2}$ mixing ratio (pptv) } & \multicolumn{2}{|c|}{$\begin{array}{c}\mathrm{I}_{2} \text { emission rates } \\
\left(\mathrm{pmol} \min ^{-1} \mathrm{gFW}^{-1}\right)\end{array}$} \\
\hline & & & & $\begin{array}{r}\text { Flush } \\
\text { (mean) }\end{array}$ & $\begin{array}{r}\text { Sample } \\
\text { (mean) }\end{array}$ & $\begin{array}{r}\text { Sample } \\
\text { (peak) }\end{array}$ & $\begin{array}{r}\text { Sample } \\
\text { (mean) }\end{array}$ & $\begin{array}{r}\text { Sample } \\
\text { (peak) }\end{array}$ \\
\hline Dictyopteris membranacea & 180 & 12 & Below detection limit (see Fig. 3a). & $0 \pm 24$ & $2 \pm 26$ & - & $0.0012 \pm 0.016$ & - \\
\hline Fucus serratus & 580 & 14 & Below detection limit & $1 \pm 24$ & $20 \pm 33$ & - & $0.0039 \pm 0.0065$ & - \\
\hline Fucus vesiculosus & 500 & 10 & $\begin{array}{l}\text { Small signal }(\sim 50 \text { pptv }) \text { appears after } \\
5 \text { min, remains close to detection limit. }\end{array}$ & $4 \pm 21$ & $34 \pm 31$ & - & $0.0079 \pm 0.0072$ & - \\
\hline Ascophyllum nodosum & 460 & 17 & $\begin{array}{l}\text { Gentle rise up to constant } \sim 300 \text { pptv over } \\
10 \text { min. (see Fig. } 3 b \text { ). }\end{array}$ & $2 \pm 21$ & $254 \pm 42$ & $416 \pm 89$ & $0.063 \pm 0.017$ & $0.104 \pm 0.030$ \\
\hline $\begin{array}{l}\text { Saccharina latissima } \\
\text { ( } 3 \text { plants, partly decayed) }\end{array}$ & 260 & 21 & $\begin{array}{l}\text { Gentle rise up to } \sim 170 \mathrm{pptv} \text { over } \\
\text { duration of the experiment }\end{array}$ & $-14 \pm 23$ & $125 \pm 28$ & $225 \pm 40$ & $0.055 \pm 0.017$ & $0.099 \pm 0.026$ \\
\hline $\begin{array}{l}\text { Saccharina latissima } \\
\text { (1 large plant, decayed) }\end{array}$ & 300 & 12 & $\begin{array}{l}\text { Small signal } \sim 60 \text { pptv in first } 5 \mathrm{~min} \text {, } \\
\text { then decays to below detection limit }\end{array}$ & $-4 \pm 24$ & $38 \pm 26$ & - & $0.015 \pm 0.010$ & - \\
\hline $\begin{array}{l}\text { Saccharina latissima } \\
\text { (1 small healthy plant) }\end{array}$ & 60 & 36 & $\begin{array}{l}\text { Immediate emission of } \sim 300 \text { pptv, rises } \\
\text { to } \sim 500 \text { pptv after } 15 \text { min, then } \\
\text { decays to } \sim 150 \text { pptv (see Fig. } 3 \mathrm{c} \text { ) }\end{array}$ & $5 \pm 23$ & $290 \pm 51$ & $528 \pm 86$ & $0.55 \pm 0.15$ & $1.01 \pm 0.26$ \\
\hline Laminaria digitata & 300 & 38 & $\begin{array}{l}\text { Immediate strong emission, decreases } \\
\text { with half-life of } 8 \mathrm{~min} \text { (see Fig. } 4 \mathrm{a} \text { ) }\end{array}$ & $2 \pm 18$ & $8300 \pm 1300$ & $23600 \pm 3700$ & $3.17 \pm 0.81$ & $9.03 \pm 2.30$ \\
\hline Laminaria hyperborea & 300 & 57 & $\begin{array}{l}\text { Immediate strong emission, decreases } \\
\text { with half-life of } 5 \text { min (see Fig. } 4 \mathrm{~b} \text { ). }\end{array}$ & $-4 \pm 41$ & $1760 \pm 290$ & $14300 \pm 2300$ & $0.67 \pm 0.17$ & $5.45 \pm 1.39$ \\
\hline $\begin{array}{l}\text { Laminaria hyperborea } \\
\text { (partly decayed) }\end{array}$ & 280 & 18 & $\begin{array}{l}\text { Very strong emission }(\sim 80000 \mathrm{pptv}) \\
\text { peaking after } 5 \mathrm{~min} \text {; second emission } \\
\text { peak }(\sim 65000 \mathrm{pptv}) \text { at } 9 \mathrm{~min} .\end{array}$ & $5 \pm 30$ & $47200 \pm 7500$ & $86900 \pm 13700$ & $19.3 \pm 4.9$ & $35.6 \pm 9.1$ \\
\hline
\end{tabular}

profile for S. latissima (Fig. 3c). Conversely no $\mathrm{I}_{2}$ emissions were detectable from the D. membranacea sample (Fig. 3a). In addition to the tick marks denoting $\mathrm{I}_{2}$ mixing ratios on the main vertical axis, each time series plot gives the corresponding $\mathrm{I}_{2}$ emission rates on the right hand axis in units of picomoles of $I_{2}$ emitted per minute per gramme fresh weight of the sample $\left(\mathrm{pmol} \mathrm{min}^{-1} \mathrm{gFW}^{-1}\right)$. Since emission rates take account of the sample's weight and the volumetric flow rate through the apparatus, they provide a more directly comparable quantity than mixing ratios when considering the results of different experiments and when comparing the results of this work with previous studies. Consequently, the single S. latissima plant $(60 \mathrm{~g})$ of Fig. $3 \mathrm{c}$ is an approximately $\times 10$ more potent emitter of $\mathrm{I}_{2}$ than the $460 \mathrm{~g}$ Ascophyllum sample of Fig. $3 b$ even though their measured peak $\mathrm{I}_{2}$ mixing ratios only differ by around a factor of two. The summary Table 1 provides emission rates along side the measured $I_{2}$ mixing ratios for all ten incubation experiments performed on the whole seaweed plants, listing the different species in approximate order of increasing emission rates. Table 1 also includes the peak $\mathrm{I}_{2}$ mixing ratios and peak emission rates for samples whose emission profiles possessed an obvious maximum. Note that the uncertainties quoted for the emission rates in Table 1 are proportionately larger than the corresponding uncertainties quoted for the mixing ratios because they incorporate an additional uncertainty associated with measuring the gas flow rate through the apparatus.
Figure 4 shows $I_{2}$ time series for samples of $L$. digitata and L. hyperborea, both of which were found to produce substantial amounts of $I_{2}$. The profiles in Fig. 4 are characterised by an immediate, very strong burst of $I_{2}$ with mixing ratios peaking in excess of $10000 \mathrm{pptv}$, i.e. $\left[\mathrm{I}_{2}\right]>10 \mathrm{ppbv}$ (parts per billion by volume, $10^{-9}$ mixing ratio). The strong $\mathrm{I}_{2}$ burst is followed by an approximately exponential decay with fitted half-lives of 8 and $5 \mathrm{~min}$ for L. digitata and L. hyperborea respectively (see insets in Fig. 4). The peak emission rates for these samples are approximately an order of magnitude larger again that the peak emission rate of the S. latissima sample in Fig. 3c, although S. latissima has a broader emission profile. A second experiment was performed on a partially decayed $L$. hyperborea specimen towards the end of the campaign (last entry in Table 1): this sample produced a peak $I_{2}$ mixing ratio of 87000 pptv, the largest of all of the seaweed incubation experiments, and sustained a double peaked emission profile over the $18 \mathrm{~min}$ duration of the experiment.

The flushed cavity data shown in the $\mathrm{I}_{2}$ time series plots of Figs. 3 and 4 perform two important quality assurance roles. First, the scatter in these data about their mean provides the most direct measure of the $\mathrm{I}_{2}$ detection limit in each experiment. For example, for Fig. 3a, the standard deviation in the whole set of flush data points before and after the seaweed sample is $24 \mathrm{pptv}$. This value is reported in Table 1 as the uncertainty in the mean mixing ratio for the flushed cavity data, and is typical of the $\mathrm{I}_{2}$ detection limits in this work. (For comparison, the average error bar on the flush data points in Fig. $3 \mathrm{a}$ is \pm 19 pptv, indicating that the $1 \sigma$ 
Table 2. Iodine mixing ratios, emission profiles and emission rates observed during the Laminaria digitata stress factor experiments.

\begin{tabular}{|c|c|c|c|c|c|c|c|c|}
\hline \multirow[t]{2}{*}{ Experiment } & \multirow{2}{*}{$\begin{array}{l}\text { Fresh } \\
\text { weight } \\
(\mathrm{g})\end{array}$} & \multirow[t]{2}{*}{$\begin{array}{l}\text { Stress } \\
\text { factor }\end{array}$} & \multirow[t]{2}{*}{$\begin{array}{l}\text { Duration } \\
\text { (min) }\end{array}$} & \multirow[t]{2}{*}{$\mathrm{I}_{2}$ emission profile } & \multicolumn{2}{|c|}{$\mathrm{I}_{2}$ mixing ratio (pptv) } & \multicolumn{2}{|c|}{$\begin{array}{c}\mathrm{I}_{2} \text { emission rates } \\
\left(\mathrm{pmol} \mathrm{min}^{-1} \mathrm{gFW}^{-1}\right)\end{array}$} \\
\hline & & & & & $\begin{array}{r}\text { Sample } \\
(\text { mean })\end{array}$ & $\begin{array}{r}\text { Sample } \\
\text { (peak) }\end{array}$ & $\begin{array}{l}\text { Sample } \\
\text { (mean) }\end{array}$ & $\begin{array}{r}\text { Sample } \\
\text { (peak) }\end{array}$ \\
\hline \multirow[t]{2}{*}{$\begin{array}{l}\# 1 \\
(27 \text { Sep 2006) }\end{array}$} & \multirow[t]{2}{*}{21} & $\begin{array}{l}\text { air } \\
\text { exposure }\end{array}$ & 20 & $\begin{array}{l}\text { Immediate strong emission, decreases exponentially with half- } \\
\text { life of } 1.6 \mathrm{~min} \text {. No detectable aerosol particle production } \\
\text { (see Fig. 5). }\end{array}$ & $314 \pm 59$ & $2330 \pm 370$ & $2.98 \pm 0.83$ & $22.1 \pm 5.7$ \\
\hline & & $\begin{array}{l}\text { ozone } \\
\text { (90 ppbv) }\end{array}$ & 23 & $\begin{array}{l}\mathrm{I}_{2} \text { emissions resume with a broader profile than air-exposure } \\
\text { stress, slower decay with half-life of } 5.2 \text { min. Peak in } \\
\text { aerosol particles }\left(140000 \mathrm{~cm}^{-3}\right) \text { corresponds with peak in } \mathrm{I}_{2} \\
\text { (see Fig. 5). }\end{array}$ & $216 \pm 41$ & $615 \pm 99$ & $2.05 \pm 0.57$ & $5.84 \pm 1.50$ \\
\hline $\begin{array}{l}\# 2 \\
(28 \text { Sep 2006) }\end{array}$ & 21 & $\begin{array}{l}\text { air } \\
\text { exposure } \\
\text { then ozone } \\
(90 \text { ppbv) }\end{array}$ & 52 & $\begin{array}{l}\text { Sample from experiment \#1 was left in sea water to recover } \\
\text { overnight and then re-used in \#2 } \\
\text { Exposure to air initially produced } \mathrm{I}_{2} \text { mixing ratios up to } \sim 900 \mathrm{pptv} \\
\text { in multiple bursts, decays to } \sim 70 \mathrm{pptv} \text { (relative to offset in early } \\
\text { cavity flush data). Exposure to ozone produced a sustained } \\
\text { emission peaking at } \sim 450 \mathrm{pptv} \text { approx } 40 \text { min after ozone } \\
\text { added. Few particles ( }<100 \mathrm{~cm}^{-3} \text { ) until } 40 \text { min, then } \\
80000 \mathrm{~cm}^{-3} \text { peaking together with } \mathrm{I}_{2} \text { (see Fig. } 6 \text { ). }\end{array}$ & $227 \pm 41$ & $450 \pm 73$ & $2.15 \pm 0.58$ & $4.27 \pm 1.10$ \\
\hline \multirow{3}{*}{$\begin{array}{l}\# 3 \\
(28 \text { Sep } 2006) \\
\# 4 \\
(28 \text { Sep } 2006)\end{array}$} & 20 & air + GG & 32 & $\begin{array}{l}\text { Immediate strong emission of } \sim 2500 \mathrm{pptv} \text {, followed by } \\
\text { exponential decrease with half-life } \approx 3.2 \text { min. }\end{array}$ & $330 \pm 60$ & $2510 \pm 400$ & $3.29 \pm 0.89$ & $25.0 \pm 6.4$ \\
\hline & \multirow[t]{2}{*}{14} & \multirow[t]{2}{*}{$\begin{array}{l}\text { air }+ \text { GG } \\
+ \text { ozone at } \\
90 \text { ppbv }\end{array}$} & \multirow[t]{2}{*}{145} & $\begin{array}{l}\text { Immediate very strong emission of } \sim 25000 \text { pptv } \mathrm{I}_{2} \text {, decaying to } \\
\text { shallow minimum of } \sim 1500 \text { pptv after } 20 \text { min. Second broad, } \\
\text { intense } \mathrm{I}_{2} \text { peak }(\sim 20000 \mathrm{pptv}) \text { appears without any apparent } \\
\text { increase in stress factors, and is sustained over next }\end{array}$ & $5430 \pm 860$ & $\begin{array}{r}26900 \pm 4300 \\
\quad \text { (first max) }\end{array}$ & $77.8 \pm 19.8$ & $\begin{array}{r}386 \pm 98 \\
\text { (first max) }\end{array}$ \\
\hline & & & & $\begin{array}{l}40 \mathrm{~min} \text {. Particle production }\left(2 \times 10^{5} \text { to } 1 \times 10^{6} \mathrm{~cm}^{-3}\right) \text { continues } \\
\text { until seaweed reactor \& aerosol growth vessel covered with } \\
\text { black cloth at } 110 \mathrm{~min} \text { (see Fig. } 7 \text { ). }\end{array}$ & & $\begin{array}{l}19400 \pm 3100 \\
\text { (second max) }\end{array}$ & & $\begin{array}{r}279 \pm 71 \\
(\text { second max) }\end{array}$ \\
\hline
\end{tabular}

GG stress: sample anointed with $10 \mathrm{~cm}^{3}$ of GG solution $\left(150 \mu \mathrm{g} \mathrm{cm}^{-3}\right)$ for $1 \mathrm{~min}$, rinsed in sea water and then loaded into the flow reactor vessel.

gradient error from the DOAS retrieval slightly underestimates the measurement's statistical uncertainty.) The average $\mathrm{I}_{2}$ concentration for the sample data points in Fig. 3a is only 2 pptv (standard deviation $=26 \mathrm{pptv}$ ), and thus it is easy to conclude that this sample of $D$. membranacea did not emit detectable amounts of $\mathrm{I}_{2}$. Secondly, the long-term stability of the BBCEAS system can be gauged by comparing the flush data points before and after sampling from the seaweed vessel, and usually any systematic drifts were negligible within the scatter of the flush data points. However, sometimes after an experiment on a large $I_{2}$ emitter the flushed cavity data points would lie significantly above zero and would be accompanied by $\mathrm{I}_{2}$ structure remaining in the BBCEAS spectra (e.g. the positive offset in the final flushed cavity data points in Fig. 4a). This was attributed to small amounts of residual $I_{2}$ coating the internal surfaces of the apparatus: in these instances, the Nalgene sample bottle and the tube surrounding the cavity were rinsed with distilled water and dried before the next experiment and the $\frac{1}{4}$ inch diameter Teflon delivery tube was replaced.

The remaining entries in Table 1 summarise two experiments performed on Fucus samples and two experiments on partially decayed $S$. latissima plants. No statistically significant $\mathrm{I}_{2}$ emission was detected from $F$. serratus, and only small amounts of $\mathrm{I}_{2}$ (max $\sim 50 \mathrm{pptv}$ ) close to the detection limit were observed from $F$. vesiculosus. Both of the decayed S. latissima samples showed clear evidence of $\mathrm{I}_{2}$ emission, though at substantially lower rates than the healthy young specimen whose emission profile appears in Fig. 3c. Whilst the decayed samples may be under-representative of $S$. latissima's usual $\mathrm{I}_{2}$ emission rates, their entries are retained in Table 1 to illustrate the following point. The $\mathrm{I}_{2}$ emission rates for the three $S$. latissima samples span more than a factor of ten (i.e. comparable to the differences between species). It seems likely therefore that $I_{2}$ emission rates depend on the age and/or health of the plant. In partial support of this idea, the dry weight iodine content of $L$. digitata is known to be higher in small, young plants (Ar Gall et al., 2004). However it is not necessarily the case that damaged plants are smaller emitters because, as noted above, the partially decayed $L$. hyperborea sample produced considerably more $\mathrm{I}_{2}$ than its healthy counterpart.

\subsection{Laminaria digitata exposed to stress factors}

A second distinct set of experiments were performed on fragments of $L$. digitata thalli exposed to various stress factors inside the flow reactor. Time profiles of the $\mathrm{I}_{2}$ emissions measured by BBCEAS (also at $7.5 \mathrm{~s}$ time resolution) are shown for three of these experiments in Figs. 5 to 7 . Additionally, Table 2 summarises the peak and averaged $I_{2}$ mixing ratios for all four stress experiments, together with pertinent information about the ozone mixing ratio and aerosol particle number concentrations co-measured in the gas flow. 

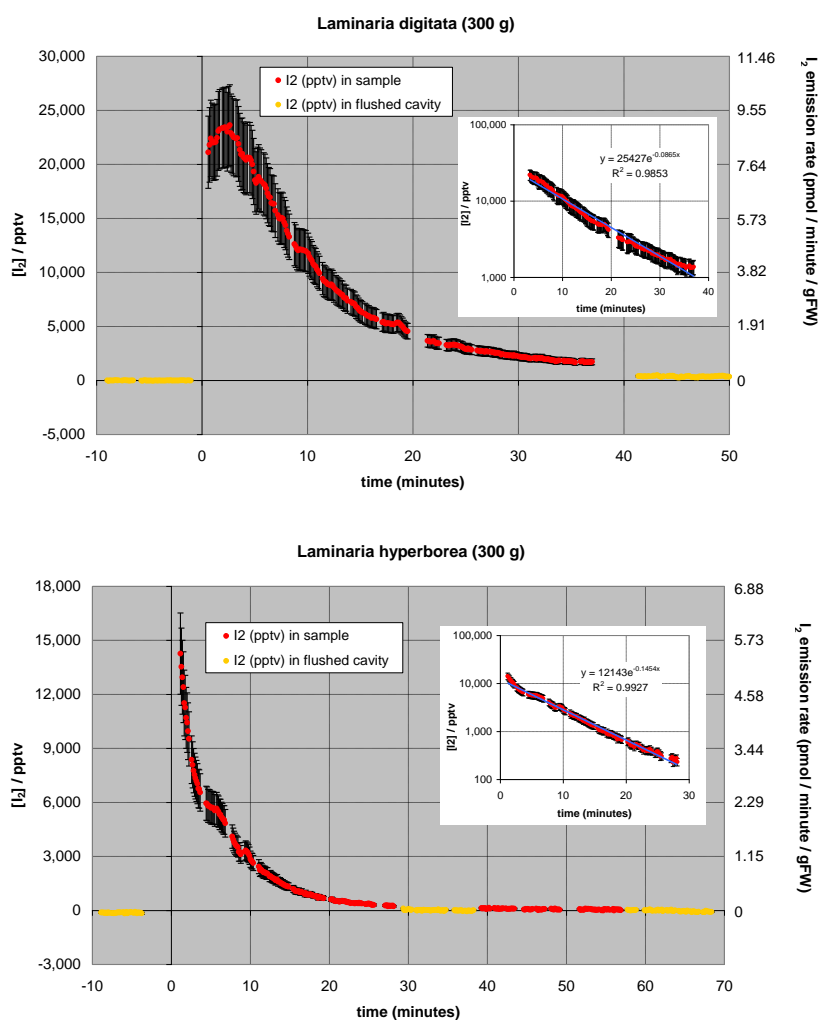

Fig. 4. Time series of the $I_{2}$ mixing ratios (left axis) and corresponding $\mathrm{I}_{2}$ emission rates (right axis) observed from Laminaria digitata (top) and Laminaria hyperborea (bottom: healthy sample). The insets show the $\mathrm{I}_{2}$ mixing ratios re-plotted on a logarithmic scale: the straight line overlaying these data points are fits to exponential decays from which the emission half-lives were estimated.

Table 2 also provides corresponding $\mathrm{I}_{2}$ emission rates calculated from the measured mixing ratios, the sample's fresh weight and the volumetric gas flow through the apparatus.

In the first experiment, two pieces of thalli (total $21 \mathrm{~g}$ fresh weight) were exposed to desiccation in air for $20 \mathrm{~min}$, after which 90 ppbv of ozone was added to the gas flow. The $\mathrm{I}_{2}$ emission profile is shown in Fig. 5. The seaweed initially produced an intense emission burst (peak $\left[\mathrm{I}_{2}\right] \approx 2300 \mathrm{pptv}$ ) that relaxed rapidly with a half-life of $\sim 1.6 \mathrm{~min}$. Note that ozone was scrubbed from the air supply for all of the stress experiments, and this first phase of stress experiment \#1 was conducted under ozone-free conditions. After normalising for weight, the averaged $\mathrm{I}_{2}$ emission rate of these $L$. digitata fragments in response to air-exposure $\left(2.98 \pm 0.83 \mathrm{pmol} \mathrm{min}^{-1} \mathrm{gFW}^{-1}\right.$ ) was same as the emission rate observed in the incubation experiment performed on a whole plant $\left(3.17 \pm 0.81 \mathrm{pmol} \mathrm{min}^{-1} \mathrm{gFW}^{-1}\right)$. This is an important result because it shows that mechanical stress (cutting the thallus into fragments) does not seem to influence the $\mathrm{I}_{2}$ emission rate in L. digitata. It is likely that the shorter half-life for this emission's decay compared to the incubation experiment is attributable to the gas flow's shorter residence time in the flow reactor apparatus compared to the 10 litre Nalgene bottle, rather than indicating a change in the emission dynamics.

A second phase of $I_{2}$ emission was observed to follow directly after ozone was added to the gas flow some 20 min into the experiment. Previous studies have shown that ozone elicits $\mathrm{I}_{2}$ emission from L. digitata (Palmer et al., 2005; Küpper et al., 2008), and in this case the addition of ozone caused a sample that had largely relaxed from its initial air-exposure stress to re-start emitting $\mathrm{I}_{2}$. The profile of the second ozoneinduced emission is noticeably lower (peak $\left[\mathrm{I}_{2}\right]=600 \mathrm{pptv}$ ) and broader than the air-exposure burst, but the integrated amounts of $\mathrm{I}_{2}$ emitted during the two events were similar: $\approx 50 \mathrm{pmol} \mathrm{gFW}^{-1}$ (calculated from the product of the average emission rates and the experiments' durations given in Table 2). This amount still only represents a very small fraction of the $L$. digitata sample's likely $\sim 1 \%$ iodine by dry weight (Küpper et al., 1998). The insert in the lower panel of Fig. 5 shows that no aerosol particles were detected by the condensation particle counter prior to the addition of ozone. Particle formation was however observed coincident with the second ozone-induced $\mathrm{I}_{2}$ emission, even though the $\mathrm{I}_{2}$ mixing ratios were considerably lower than for the initial air-induced $\mathrm{I}_{2}$ burst. These two regimes are clearly represented in the correlation plot of $\mathrm{I}_{2}$ mixing ratio versus particle number concentration in the main plot in the lower panel of Fig. 5: (i) a flat "arm" of the plot showing no particle formation in the absence of ozone even at high $\left[\mathrm{I}_{2}\right]$ and (ii) a second steeply-sloping arm showing a rapid, approximately linear increase in particles with $\mathrm{I}_{2}$ mixing ratio (slope $=620$ particles $\mathrm{cm}^{-3} \mathrm{pptv}^{-1}$ ) once a threshold concentration of $\mathrm{I}_{2} \approx 400 \mathrm{pptv}$ had been reached. Thus we conclude that while ozone isn't necessarily required to elicit $I_{2}$ emissions from $L$. digitata, ozone is required by the subsequent chemistry that oxidises iodine into condensable iodine oxides. This is entirely consistent with the known chemistry of the iodine oxides. The stress experiments were conducted in a largely glass apparatus under the SBR cold room's fluorescent strip lighting. Room light photolyses $\mathrm{I}_{2}$ to I atoms which then react with ozone to produce IO and thence higher oxides, the direct gas phase reaction between $\mathrm{I}_{2}+\mathrm{O}_{3}$ being very slow. (Indeed, ozone stress experiment \#4 (below and Fig. 7) will show that particle nucleation ceased immediately the seaweed reactor vessel and the aerosol growth vessel were covered with a black cloth, though the $I_{2}$ emissions continued.)

At the end of the first stress experiment, the L. digitata fragments were removed from the flow reactor and stored in aerated seawater overnight. The same fragments were then used the next day in the second experiment to test how seaweed that had previously been stressed by ozone would react to a second stress event. On initial exposure to air, the sample produced multiple bursts of several hundred pptv $\mathrm{I}_{2}$. A technical issue prevented the BBCEAS instrument from recording this initial phase, and so the emission 

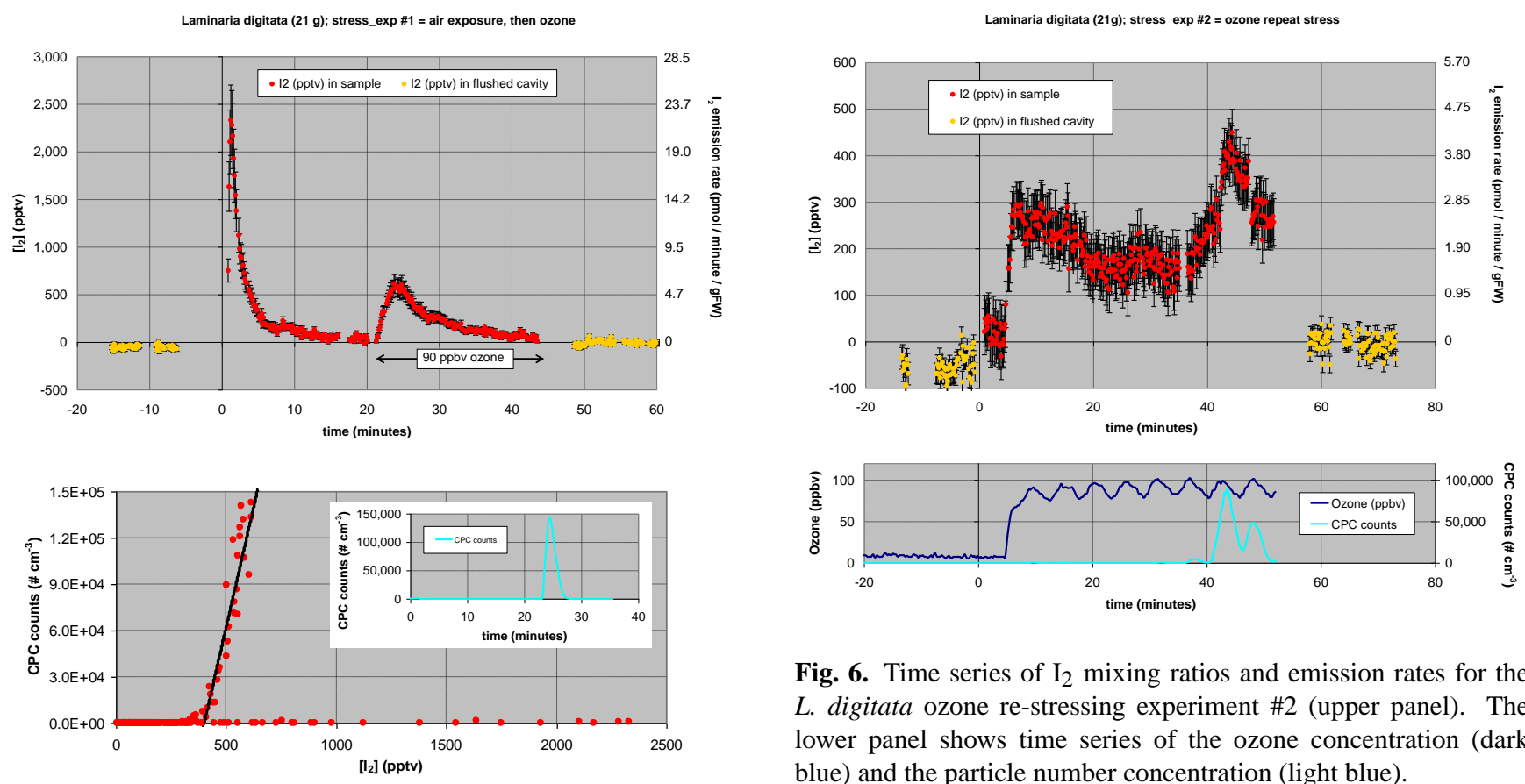

Fig. 6. Time series of $I_{2}$ mixing ratios and emission rates for the L. digitata ozone re-stressing experiment \#2 (upper panel). The lower panel shows time series of the ozone concentration (dark blue) and the particle number concentration (light blue).

Fig. 5. Time series of $I_{2}$ mixing ratios and emission rates for $L$. digitata stress experiment \#1. Ozone was scrubbed from the air flow for the first 20 minutes of the experiment, after which $\sim 90 \mathrm{ppbv}$ of ozone was added. The inset to the lower panel shows the particle formation event observed co-incident with the second ozoneinduced $\mathrm{I}_{2}$ emission burst. The lower panel also shows a correlation plot of particle counts versus $\mathrm{I}_{2}$ mixing ratio, with the heavy black line being a linear fit to the particle data during the ozone-induced emission burst.

profile in Fig. 6 begins about $30 \mathrm{~min}$ after the sample had first been exposed to air, by which time the $\mathrm{I}_{2}$ emission had relaxed to $\sim 70$ pptv (relative to an offset in the initial flush cavity data points). Ozone at $90 \mathrm{ppbv}$ was then added to the gas flow at $t=4 \mathrm{~min}$ in Fig. 6 . The $\mathrm{I}_{2}$ concentration increased abruptly to $300 \mathrm{pptv}$, but rather than following the usual exponential-type decay, a broad $\mathrm{I}_{2}$ emission was sustained for the next $50 \mathrm{~min}$ reaching a maximum of 450 pptv shortly before the end of the experiment. Very little particle production was observed until the $\mathrm{I}_{2}$ mixing ratio rose through a threshold of $\left[I_{2}\right]>205$ pptv towards the end of the experiment (lower panel of Fig. 6). Again there was an approximately linear relationship between particle number concentration and $\mathrm{I}_{2}$ mixing ratio above the threshold ( 330 particles $\mathrm{cm}^{-3} \mathrm{pptv}^{-1}$ ). The $\mathrm{I}_{2}$ emission rate averaged throughout this experiment was (within uncertainty) the same as the average emission rate for the second ozoneinduced $\mathrm{I}_{2}$ emission phase from this sample in stress experiment \#1 (see Table 2). Thus the primary effect of previously having undergone a stress event seemed to be to change the shape of the emission profile rather than to limit the sample's ability to emit $\mathrm{I}_{2}$.

A third stress experiment was performed on two fragments of freshly cut $L$. digitata thalli that had been anointed with GG solution to stimulate a response to pathogen attack. A single intense burst of $\mathrm{I}_{2}$ emission up to $2500 \mathrm{pptv}$ was observed when the samples were first placed into the flow reactor, followed by a smooth decay in the emissions with a half-life of $3.2 \mathrm{~min}$ (see Table 2). Thus, although the emission profile was slightly more prolonged, it was not significantly stronger than for the initial air-induced $\mathrm{I}_{2}$ emission in stress experiment \#1. No particle formation was observed, as expected, because ozone had been scrubbed from this experiment's air supply.

The final experiment exposed fragments of L. digitata to simultaneous air + ozone + GG stresses. This combination yielded by far the largest emission rates of any experiment in this work $(\approx \times 10$ larger peak emission rate than even the incubation experiment on the partially decayed $L$. hyperborea sample). The top panel of Fig. 7 shows a very intense initial burst of $25000 \mathrm{pptv}$ of $\mathrm{I}_{2}$, followed by a sustained period of smaller but nevertheless still quite strong emissions ( $\left.\mathrm{I}_{2} \approx 1500 \mathrm{pptv}\right)$. Then $35 \mathrm{~min}$ into experiment \#4, and without any apparent increase in the stress factors, the $\mathrm{I}_{2}$ emissions increase again: $\mathrm{I}_{2}$ mixing ratios were sustained at 7000-20000 pptv for more than $40 \mathrm{~min}$, before decaying away towards the end of the experiment. Curiously, there was a third smaller burst of $I_{2}$ when the ozone was turned off around $t=120 \mathrm{~min}$ suggesting that the $L$. digitata sample reacted to the removal of a stress factor by increasing its $I_{2}$ emissions. Particle formation was observed throughout stress experiment \#4 until a black cloth was placed over the apparatus at $t=110 \mathrm{~min}$ to exclude the room light (middle 

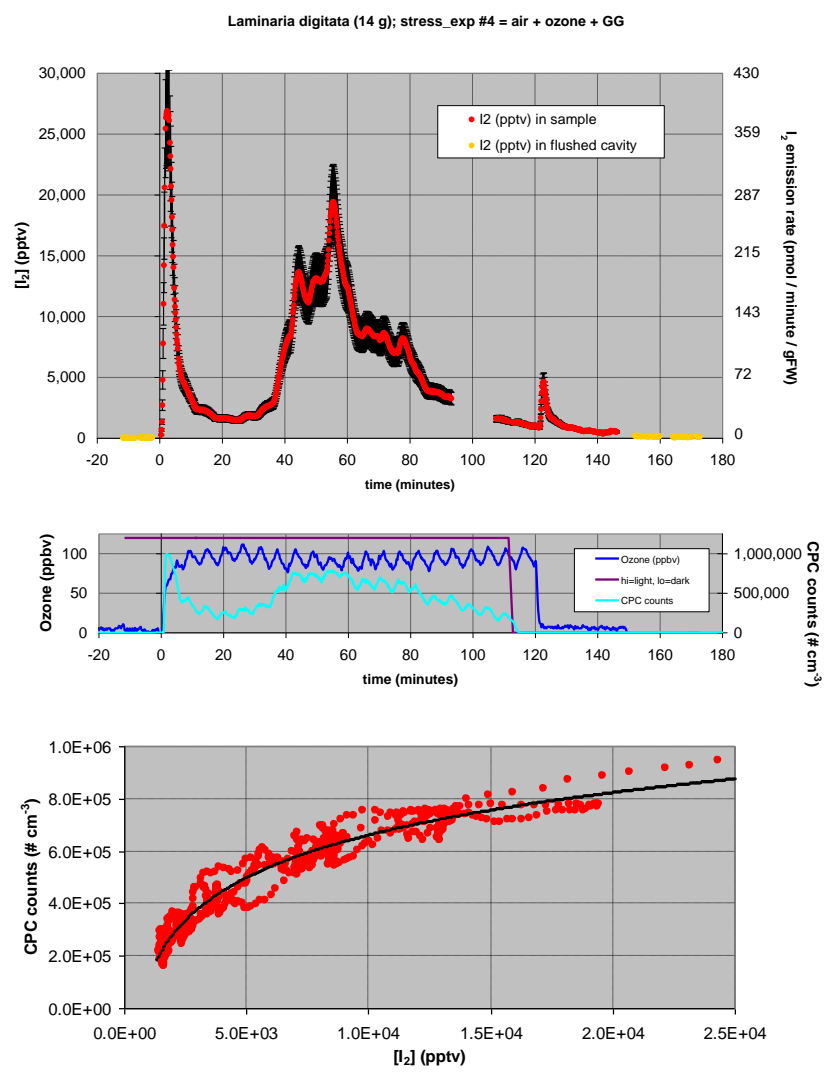

Fig. 7. Time series of $I_{2}$ mixing ratios and emission rates for the L. digitata air + ozone + GG multiple stress experiment \#4 (upper panel). The middle panel shows time series of the ozone concentration (dark blue), the particle number concentration (light blue) and whether the seaweed vessel was exposed to the room lights (purple). The bottom panel shows a correlation plot of particle counts versus $\mathrm{I}_{2}$ mixing ratio for data between $t=3$ and $110 \mathrm{~min}$ (i.e. excluding the upward part of the first strong emission event and all data after the seaweed vessel was covered). The heavy black line is a fit of the type: $\mathrm{CPC}$ counts $=\mathrm{A} \times \log \left[\mathrm{I}_{2}\right]+\mathrm{B}$.

panel of Fig. 7); but there was no noticeable change in the $\mathrm{I}_{2}$ emissions when the apparatus was covered. The particle number concentrations observed in this experiment were substantially larger than in previous experiments \#1 and \#2, no doubt due to the higher $\mathrm{I}_{2}$ mixing ratios. The bottom panel of Fig. 7 shows an approximately logarithmic relationship between particle numbers and $\mathrm{I}_{2}$ indicative of a roll-off in particle formation rates at high $\mathrm{I}_{2}$ mixing ratio.

\section{Discussion}

\subsection{Incubation studies on whole seaweed plants: species-dependent $I_{2}$ emission rates}

The incubation studies show that the various seaweed species investigated in this work yielded substantially different $\mathrm{I}_{2}$ emission rates spanning four orders of magnitude. The entries in Table 1 have been grouped by species and are listed in approximate order of increasing emission rates: $D$. membranacea $\approx F$. serratus $\leq F$. vesiculosus $<A$. nodosoum $<S$. latissima $<L$. digitata $\approx L$. hyperborea. This ranking is broadly consistent with the order in which iodine content increases within seaweed plants themselves (e.g. Küpper et al., 1998; Teas et al., 2004; Martinelango et al., 2006). But the variation in $I_{2}$ emission rates is proportionately far greater than the species-dependent differences in iodine content. For example, iodine concentrations in L. digitata plants are some 7-30 times greater than in F. vesiculosus, yet the $\mathrm{I}_{2}$ emission rates from $L$. digitata were found here to exceed those from $F$. vesiculosus by around a thousand times, suggesting that the physiological function of iodine is different in these two species. The above ranking also mirrors how the seaweed speciation changes moving seawards through the inter-tidal zone at Roscoff, with the largest emitters L. digitata and L. hyperborea living in deeper waters further from the shoreline: a map of seaweed habitats in the Roscoff area is shown in Leigh et al. (2009). As well as the inter-species differences, substantial variability was observed in $\mathrm{I}_{2}$ emission rates for the few repeat incubation experiments on the same species $(S$. latissima $\times 3$ and L. hyperborea $\times 2$ ) suggesting that $\mathrm{I}_{2}$ emissions also depend on the age and/or health of plants. Natural populations contain a distribution of ages and will inevitably include some unhealthy/damaged individuals. Each of these make their own particular contributions to the net emissions into the atmosphere, and thus more systematic future investigations of $\mathrm{I}_{2}$ emission rates ought to consider plants of different ages and condition.

During RHaMBLe, strong tidal dependences were seen in atmospheric $\mathrm{I}_{2}$ and $\mathrm{IO}$ measurements made by long path DOAS over the channel between the SBR and the Ile de Batz (Mahajan et al., 2009), and in the point measurements of $I_{2}$ (Leigh et al., 2009), IO (Whalley et al., 2007; Wada et al., 2007) and aerosol particles (Whitehead et al., 2009) located at the RHaMBLe measurement site on the jetty in front of the SBR. The various data sets are also summarised in the Roscoff overview paper introducing this RHaMBLe special issue (McFiggans et al., 2010). The modelling study of Leigh et al. (2009) sought to understand the temporal and spatial variability of $\mathrm{I}_{2}$ emission into the atmosphere by linking emission rates parameterised from this study to the distribution of seaweed habitats around Roscoff. The model provided a good qualitative and a reasonable quantitative explanation of the tidal signatures in the $I_{2}$ measurements 
in terms of the most efficient, most distant $\mathrm{I}_{2}$ emitting seaweeds only becoming exposed around the lowest low tides. It has also been observed at Cape Grim in Australia that large biomasses of the fucoid alga Durvillaea potatorum appear to play a very limited role in contributing to particle formation because, despite its common name of the southern bull kelp, this species does not emit $\mathrm{I}_{2}$ (Cainey et al., 2007). Thus the linked RHaMBLe observations/modelling and the Cainey et al. (2007) study reveal the importance algal speciation plays in understanding the iodine chemistry and resultant particle formation at a given site. Kelps are far better emitters of $\mathrm{I}_{2}$ whereas fucoids are poorer emitters and accumulators. These differences strongly suggest a link between the evolution of kelps from the order of Laminariales, which evolved more recently than the order of Fucales and Dictyopteriales (Rousseau et al., 2001), and their capacity to emit iodine. During this evolution, it seems that kelps developed new biochemical adaptations in their use of halides related to their capacity to specifically oxidise iodide using vanadiumdependent haloperoxidases. Most algae feature bromoperoxidases that can react with either bromide or iodide. However Laminariales species are the only brown algae where iodoperoxidase activities (i.e. specific for iodide) have been detected (Almeida et al., 2001; Colin et al., 2005). In these algae, the occurrence of such an enzyme (likely to be present in the apoplast) should explain (i) the very high amounts of iodide accumulated in their cell walls and (ii) their higher efficiency for enzymatic iodide oxidation with the concomitant removal of $\mathrm{H}_{2} \mathrm{O}_{2}$ produced during oxidative stresses such as exposure to air, desiccation or GG elicitation. The latter process could also explain how $\mathrm{I}_{2}$ emission can occur even in the absence of strong external oxidants such as ozone. The exception among fucoids is the genus Ascophyllum, which possess two distinct isoforms of bromoperoxidases, one of them being located very superficially at the thallus surface (Krenn et al., 1989). The existence of the external isoform may explain Ascophyllum's $\mathrm{I}_{2}$ emission rates which are not directly correlated with particularly high iodide content in this species, but instead depend on enzymatic capacities to efficiently oxidise iodide. This hypothesis agrees with the Leigh et al. (2009) modelling study which showed that the occurrence of rockweed in the mid-littoral zone of sheltered habitats complements the $I_{2}$ emissions from the large (but more distant) beds of Laminariales, the former providing a substantial fraction of the $\mathrm{I}_{2}$ detected at the RHaMBLe measurement site. Rockweed beds may also emit more constantly than kelps because they are naturally exposed more frequently (even for small tides) and for longer durations.

It is worth recalling that the present incubation experiments tried, as far as possible, to avoid applying any other stress to the plant samples beyond desiccation in ambient air to mimic the effect of the seaweeds becoming exposed at low tide. Although ozone was not scrubbed from the air supply for the incubation experiments, it was likely that the ozone concentrations were low (even compared to ambient amounts) for experiments performed in the SBR cold room. An average ozone concentration of 3 ppbv was measured during the final incubation experiment on 30 September. The $D$. membranacea and the first $L$. hyperborea (healthy specimen) incubation experiments were performed in a regular laboratory on the afternoon of 27 September when the ozone concentration outside at the RHaMBLe measurement site was between 27 and $32 \mathrm{ppbv}$, and this reasonably represents an upper limit for the ozone concentration inside the SBR building. Thus the $\mathrm{I}_{2}$ emissions observed during the incubation experiments arise from certain seaweed species responding strongly to very dilute (or at most ambient $\approx 30 \mathrm{ppbv}$ ) concentrations of ozone. An alternative explanation is that air-exposure itself (i.e. without ozone) is sufficient to trigger the seaweeds' stress response. This theory carries some weight because $I_{2}$ emissions were still observed when fragments of $L$. digitata were exposed to ozone-free scrubbed air during the first stress experiment, their weight-normalised emission rate being comparable to the rate seen in the incubation experiment on the whole L. digitata plant.

Two other groups have also reported time-resolved gasphase $\mathrm{I}_{2}$ emissions from $L$. digitata exposed to air. Dixneuf et al. (2009) performed a set of 16 chamber measurements using incoherent broadband cavity enhanced absorption spectroscopy (IBBCEAS) to quantify $\mathrm{I}_{2}$ mixing ratios above whole $L$. digitata thalli. Their chamber operated as static system filled with ambient air from the laboratory (measured $\left[\mathrm{O}_{3}\right]<15$ ppbv), and the IBBCEAS method had a $10 \mathrm{~s}$ acquisition time enabling rapid variations in $\mathrm{I}_{2}$ concentrations to be tracked. (IBBCEAS is related to the BBCEAS detection method used in this work, the major difference being the use of an arc lamp instead of an LED as the light source). The highest $\mathrm{I}_{2}$ mixing ratios (up to several $100 \mathrm{ppbv}$ ) were observed in the first $1-3 \mathrm{~h}$ after the samples were placed into the chamber. This initial part of the time profiles is similar to the immediate strong emission burst followed by a relatively smooth decay observed here for $L$. digitata exposed to air in the incubation experiment and the first desiccation-only phase of stress experiment \#1. Beyond the initial burst, the $\mathrm{I}_{2}$ time profiles were additionally characterised by a series of emission pulses with highly variable regularity and periodicity extending throughout the $20 \mathrm{~h}$ duration of the Dixneuf et al. (2009) experiments. The only occasions when secondary $\mathrm{I}_{2}$ emission bursts were observed in the present work were for the L. digitata ozone re-stressing experiment (\#2) and the multiple stress experiment (\#4), although perhaps the present profiles are too brief to observe such a phenomenon from experiments performed under more natural conditions. Further quantitative comparisons with the Dixneuf et al. (2009) study are difficult because no $\mathrm{I}_{2}$ emission rates were reported.

Bale et al. (2008) used $I_{2}$ photolysis followed by resonance fluorescence of I atoms to quantify $\mathrm{I}_{2}$ emitted by a $50 \mathrm{~g}$ sample of $L$. digitata placed in the Pyrex glass flask of a flow reactor. The seaweed sample was harvested at Mace Head and used within $30 \mathrm{~min}$, and the flow reactor operated under 
synthetic air from a cylinder (i.e. no ozone). The $\mathrm{I}_{2}$ mixing ratio peaked at around $300 \mathrm{ppbv}$ within ten minutes of the sample being placed into the flow reactor, corresponding to a very large peak emission rate of $2500 \mathrm{pmol} \mathrm{min}^{-1} \mathrm{gFW}^{-1}$. The emissions subsequently decayed away until a second $\mathrm{I}_{2}$ burst was provoked by agitating the flask. Thus the Dixneuf et al. (2009), Bale et al. (2008) and the present studies all show that $L$. digitata produces substantial amounts of $\mathrm{I}_{2}$ on exposure to air containing sub-ambient or no ozone, with the former two studies recording even higher $I_{2}$ mixing ratios than observed here.

Earlier studies have also monitored the $\mathrm{I}_{2}$ emissions from seaweeds indirectly using wet chemical detection methods with comparatively slow time responses: $15-30 \mathrm{~min}$ acquisition times for sampling $\mathrm{I}_{2}$ onto starch-coated denuder tubes (Sellegri et al., 2005) or an $\approx 1 \mathrm{~h}$ acquisition time for extraction of $\mathrm{I}_{2}$ into alkaline ethanol solution and measuring the iodide anion's absorption at $255 \mathrm{~nm}$ (Palmer et al., 2005; and discussed further by Küpper et al., 2008). The first study focussed on particle formation rates on exposure of seaweed samples to ambient air, whilst the latter focussed on $\mathrm{I}_{2}$ and halocarbon emission rates and particle production when $L$. digitata samples were exposed to stress factors (these aspects are discussed in following sections). However both studies also report $\mathrm{I}_{2}$ emission rates for seaweed samples exposed to air alone which, given the time responses of their detection methods, are best compared with $\mathrm{I}_{2}$ emission rates averaged over the present BBCEAS time series. A good level of agreement exists: the average emission rates of around $3 \mathrm{pmol} \mathrm{min}^{-1} \mathrm{gFW}^{-1}$ observed for the L. digitata incubation experiment and the desiccation-only phase of stress experiment \#1 lie within the emissions range quoted by Palmer et al. (2005) for $L$. digitata exposed to air from below their detection limit up to $9 \mathrm{pmol} \mathrm{min}^{-1} \mathrm{gFW}^{-1}$. Additionally, Sellegri et al. (2005) observed 24 pptv $I_{2}$ per kg of seaweed in chamber experiments conducted on "Laminaria $s p$. and Fucus $s p$. seaweeds widely found in the Mace Head tidal area." This equates to an $\mathrm{I}_{2}$ emission rate of about $0.8 \mathrm{pmol} \mathrm{min}^{-1} \mathrm{gFW}^{-1}$ for the $8001 \mathrm{~min}^{-1}$ flow rate through their seaweed chamber, which is in reasonable agreement with the present results for $L$. digitata but substantially larger than for either of the fucoid species investigated here.

\subsection{Laminaria digitata exposed to stress factors: $I_{2}$ emission rates}

Comparisons can also be made with the work of Palmer et al. (2005) for experiments where L. digitata samples were exposed to stress factors. For exposure to $90 \mathrm{ppbv}$ of ozone, we observed average emission rates of $2.05 \pm 0.57 \mathrm{pmol} \mathrm{min}^{-1} \mathrm{gFW}^{-1}$ for the second ozoneinduced $\mathrm{I}_{2}$ emission phase in stress experiment $\# 1$ and $2.15 \pm 0.58 \mathrm{pmol} \mathrm{min}^{-1} \mathrm{gFW}^{-1}$ for the ozone re-stressing experiment \#2, both of which were similar to the average emission rates observed for $L$. digitata exposed to air alone
(3.17 \pm 0.81 and $2.98 \pm 0.83 \mathrm{pmol} \mathrm{min}^{-1} \mathrm{gFW}^{-1}$ ). Palmer et al. (2005) observed a comparable $2.9 \mathrm{pmol} \mathrm{min}^{-1} \mathrm{gFW}^{-1}$ for $80 \mathrm{ppbv}$ of ozone, a value which, like the present ozone data, lies within the range of emission rates Palmer et al. measured for their samples exposed to air alone. All of the present ozone exposure experiments were conducted at $\left[\mathrm{O}_{3}\right] \approx 90 \mathrm{ppbv}$, so this study provides no further information on how $\mathrm{I}_{2}$ emissions scale with ozone concentration. Palmer et al. (2005) did observe $I_{2}$ emission rates up to $130 \mathrm{pmol} \mathrm{min}^{-1} \mathrm{gFW}^{-1}$ at $\left[\mathrm{O}_{3}\right]=160 \mathrm{ppbv}$, and the only occasion such large emission rates were encountered in the present study was for the air + ozone + GG multiple stress experiment \#4 (average and peak emission rates of 78 and $390 \mathrm{pmol} \mathrm{min}^{-1} \mathrm{gFW}^{-1}$ respectively). Very recently Huang et al. (2010) observed increased emission of $I_{2}$ with increasing ambient ozone mixing ratios from seaweeds growing in Mweenish Bay on the west coast of Ireland, nearby Mace Head (here the dominant species are A. nodosum and F. vesiculosus).

Whereas Palmer et al. (2005) observed enhanced $\mathrm{I}_{2}$ emission rates up to $38 \mathrm{pmol} \mathrm{min}^{-1} \mathrm{gFW}^{-1}$ in response to GG stress, the average $I_{2}$ emission rate measured in this work for GG stress $\left(3.29 \pm 0.89 \mathrm{pmol} \mathrm{min}^{-1} \mathrm{gFW}^{-1}\right)$ was essentially the same as for air-exposure alone. L. digitata has been shown to release large amounts of iodide into the aqueous phase in response to GG, e.g. $2.7 \times 10^{-7} \mathrm{~mol}\left(\mathrm{I}_{(\mathrm{aq})}^{-}\right) \mathrm{gFW}^{-1}$ over a 30 min period (Küpper et al., 2008), and so presumably the present sample did likewise. Apart from innate biological variability, the only explanation we offer for the apparently low $\mathrm{I}_{2}$ emission rates seen in our GG stress experiment is that it is possible that the availability of a suitable oxidant was sufficiently limited under the ozone-scrubbed conditions of our GG experiment \#3 that only a small fraction of the emitted $\mathrm{I}_{(\mathrm{aq})}^{-}$was oxidised into gas phase molecular iodine. The difference in the apparent $\mathrm{I}_{2}$ emission rates between the Palmer et al. (2005) and the present GG experiments could be explained if the iodide released by the L. digitata samples formed another iodine-containing gas, such as HOI, that would have also been collected by the alkaline extraction method employed by Palmer et al. but that would not be detected by the present BBCEAS instrument which is specific to gas phase $\mathrm{I}_{2}$. Indeed it is not yet known which oxidised iodine species $-\mathrm{I}_{2}$ or $\mathrm{HOI}$ or $\mathrm{I}_{3(\mathrm{aq})}^{-}$or a mixture of these - is produced by the haloperoxidase enzymes, although a recent computational modelling study suggests HOI is the thermodynamically favoured product of iodoperoxidase (Pacios and Galvez, 2010). It is interesting to note that ten-fold larger $\mathrm{I}_{2}$ emissions were subsequently observed when the same GG stress was accompanied by 90 ppbv of ozone in stress experiment \#4. 


\subsection{Laminaria digitata exposed to stress factors: particle formation rates}

Particle formation was seen in all L. digitata stress experiments where ozone was added, subject to the $\mathrm{I}_{2}$ mixing ratios being above certain threshold values. Particle production tracked the $\mathrm{I}_{2}$ emissions closely, with both the large scale variations in $\mathrm{I}_{2}$ and the more rapid periodic behaviour (especially in experiment \#4) being reflected in the particle numbers. Approximately linear relationships were observed between $I_{2}$ and particle number concentrations once the $I_{2}$ mixing ratios exceeded 400 and 200 pptv in ozone stress experiments \#1 and \#2, respectively. However, the greatest aerosol production corresponded with the very high $\mathrm{I}_{2}$ mixing ratios observed during the multiple air + ozone + GG stress experiment \#4. Here particle number concentrations were maintained between 200000 and $800000 \mathrm{~cm}^{-3}$ until the apparatus was covered after $110 \mathrm{~min}$ to exclude the room light. That no change was apparent in the $\mathrm{I}_{2}$ emissions when light was excluded but that particle formation ceased immediately (middle panel of Fig. 7) indicates that light is required to initiate the particle-forming iodine oxidation chemistry but is seemingly not necessary for the $\mathrm{I}_{2}$ emission itself. In contrast to the linear relationships in experiments \#1 and \#2, the bottom panel of Fig. 7 shows a roll-off in particle numbers suggesting that coagulation and/or condensational growth was capping the number concentration at high $\left[\mathrm{I}_{2}\right]$. Sellegri et al. (2005) used a nano-scanning mobility particle sizer (SMPS) to monitor the diameter of particles formed in their chamber study and did indeed observe larger particles at high seaweed loadings (i.e. at higher $\mathrm{I}_{2}$ concentrations). The same authors also report a linear relationship of 2800 particles $\mathrm{cm}^{-3} \mathrm{pptv}^{-1}$ between particle production and $\mathrm{I}_{2}$ concentration between $0-400$ pptv $\mathrm{I}_{2}$ but with no apparent threshold behaviour (cf. 620 particles $\mathrm{cm}^{-3} \mathrm{pptv}^{-1}$ above threshold for experiment \#1 in the bottom panel of Fig. 5). An approximately linear relationship was also reported by Palmer et al. (2005) and Küpper et al. (2008) between total integrated particle numbers and varying amounts of $\mathrm{I}_{2}$ emission from $L$. digitata exposed to differing ozone concentrations. Interestingly, no correlation was found between particle numbers and total iodocarbon concentrations showing that the particles' source gas is $I_{2}$ rather than iodocarbons, a result that is confirmed by the close relationship between $\mathrm{I}_{2}$ mixing ratios and particle numbers found in our study. Palmer et al. (2005) also noted significant inter-sample variability in particle production rates for equivalent amounts of ozone, and attributed this to biological variability in the $L$. digitata samples. Non-linear processes in the iodine oxidation chemistry (e.g. the bimolecular self-reaction of IO) and in the nucleation kinetics (e.g. the roll-off behaviour in Fig. 7) are expected to further amplify the effect that biological variability in $\mathrm{I}_{2}$ emission exerts on particle formation rates. Similarly the occurrence of any threshold behaviour for nucleation, the values of the threshold $\mathrm{I}_{2}$ amounts and the linear (or otherwise) relationship between $\mathrm{I}_{2}$ amounts and particle numbers depend in complex ways on experimental conditions (e.g. the photolysis rate of $I_{2}$ and thus the flux of I atoms, the time allowed for particles to grow to detectable sizes, etc). Whilst a thorough understanding of the nucleation mechanism ought to be able to reproduce experimental observations, the observations themselves remain properties of the experimental system and thus are not directly relevant to particle nucleation under ambient conditions, except for providing data to further refine nucleation theory.

Overall, the available studies show a consistent pattern that increased $\mathrm{I}_{2}$ emissions lead to greater particle production. Key results from the present study are that (i) $I_{2}$ emissions from the largest emitters, L. digitata, L. hyperborea and to a lesser extent $S$. latissima, are strongly varying functions of time, and (ii) variations in $\mathrm{I}_{2}$ mixing ratios have been shown to translate directly onto highly time dependent particle formation rates in the $L$. digitata ozone stress experiments. The idea that particle formation occurs in localised emission hot-spots was proposed by Burkholder et al. (2004) to reconcile the high IO concentrations required to model particle nucleation from OIO in their laboratory experiments with the much lower IO amounts detected in the atmosphere over extended DOAS light paths. Additionally, Saiz-Lopez et al. (2006) modelled iodine oxide clustering to form particles and concluded that the majority of $\mathrm{I}_{2}$ emission and particle nucleation was located in only $8 \%$ of their $4.2 \mathrm{~km}$ DOAS light path used at the NAMBLEX campaign (i.e. above the inter-tidal zone where the seaweeds have their main habitats). The present results corroborate the hot-spot hypothesis: atmospheric $\mathrm{I}_{2}$ emissions are likely to be localised over plants of the most efficiently emitting kelp species and localised in time being strongest when the seaweeds are first uncovered by the ebbing tide. And it is this combination of spatially and temporally localised concentrations of condensable iodine precursors that facilitates particle nucleation.

Unfortunately, no clear relationship between ozone deposition and $\mathrm{I}_{2}$ emission emerges from this work. There is a modest anti-correlation between $\mathrm{O}_{3}$ and $\mathrm{I}_{2}$ in Fig. 7, e.g. the shallow dip in $\mathrm{O}_{3}$ concentration around the prolonged second $\mathrm{I}_{2}$ emission event, and this could be explained by greater $\mathrm{O}_{3}$ deposition onto the seaweed's surface increasing the rate of inorganic reactions like $\mathrm{I}_{(\mathrm{aq})}^{-}+\mathrm{O}_{3}$ that liberate $\mathrm{I}_{2}$ into the gas phase. Support for that causal link is, however, obscured by periodic structure in the $\mathrm{O}_{3}$ time series and a corresponding in-phase periodicity to the $\mathrm{I}_{2}$ emissions. As noted above, this periodic structure also appears (in phase) in the particle counts because particle formation depends on both $\mathrm{I}_{2}$ and $\mathrm{O}_{3}$. Periodic structure is also seen in the ozone time series in the stress experiment \#2 and in the particle counts once nucleation starts towards the end of the experiment (lower panel of Fig. 6). Oscillatory behaviour in particle production rates has been observed in previous chamber studies exposing $L$. digitata to ozone (Küpper et al., unpublished work; as discussed in Palmer et al., 2005). The origin of this behaviour remains 
unclear, however it may be related to periodic changes in the $\mathrm{O}_{3}$ deposition rate onto the seaweed's surface (and hence have a biological component) because no such undulations are observed in aerosol nucleation experiments that use iodine crystals as their $\mathrm{I}_{2}$ source (G. McFiggans, personal communication, 2009).

\section{Conclusions}

$\mathrm{I}_{2}$ emissions from seven different seaweed species were investigated during ten incubation experiments aimed at mimicking exposure of seaweed plants to air at low tide. Seaweed samples were taken directly from the beach immediately prior to the experiment or were harvested from the intertidal zone and stored in the seawater aquarium at the Station Biologique de Roscoff. All experiments were performed on whole seaweed plants in order to minimise the stress experienced by the samples. An additional four experiments investigated $\mathrm{I}_{2}$ emission and particle formation from $L$. digitata exposed to desiccation in air, ozone and oligoguluronate stress factors. The various experiments were performed during the final week of the RHaMBLe Roscoff deployment, and generally it was impractical within that time constraint to repeat individual experiments. Nevertheless some general conclusions may be drawn:

(i) Substantial differences were observed in the $I_{2}$ emission rates for the various seaweed species on exposure to air. $\mathrm{I}_{2}$ emissions spanned four orders of magnitude and increased in the order: Dictyopteris membranacea $\approx$ Fucus serratus $\leq$ Fucus vesiculosus $<$ Ascophyllum nodosoum < Saccharina latissima $<$ Laminaria digitata $\approx$ Laminaria hyperborea. The most potent emitters (L. digitata and L. hyperborea) produced $\mathrm{I}_{2}$ mixing ratios peaking between 15000 and 87000 pptv. Direct spectroscopic detection of $\mathrm{I}_{2}$ at levels of a few hundred pptv was also confirmed from S. latissima and A. nodosum. No emissions of $\mathrm{I}_{2}$ were detectable from $D$. membranacea or $F$. serratus, and at most only modest emissions were observed from $F$. vesiculosus (max. $\approx 50$ pptv compared to the BBCEAS detection limit of 25 pptv). There is also evidence that $\mathrm{I}_{2}$ emissions depend on the age/physiological state of the plant. These incubation experiments were performed under conditions of low ozone $\left(\left[\mathrm{O}_{3}\right] \approx 3 \mathrm{ppbv}\right.$ in the cold room) or at most ambient $\approx 30$ ppbv concentrations. Exposure to ozone has previously been shown to be a strong external oxidative stress for L. digitata (McFiggans et al. 2004; Palmer et al., 2005; Küpper et al., 2008) which produces $\mathrm{I}_{2}$ via inorganic reaction of ozone with iodide released from the plant's accumulated stock. However the present low-ozone incubation experiments additionally suggests that $I_{2}$ is a product of detoxification processes involving haloperoxidase enzymes that certain seaweed species use to counter internal oxidative stresses due to exposure to air alone. A combination of inorganic and enzymetic production of $\mathrm{I}_{2}$ seems likely in the seaweed's natural environment when plants are exposed to ambient air at low tides.

(ii) The fast time resolution of the BBCEAS detection method $(7.5 \mathrm{~s})$ allowed the time dependence of the $\mathrm{I}_{2}$ emission to be investigated. The large emitters tended to produce a burst of $\mathrm{I}_{2}$ when first exposed to air. This phenomenon had been observed previously for L. digitata (Bale et al., 2008; Dixneuf et al., 2009) and this work shows that L. hyperborea behaves similarly. S. latissima exhibited a more broadly peaked $\mathrm{I}_{2}$ time profile and $A$. nodosum produced $\mathrm{I}_{2}$ emissions tending towards a steady plateau. The shape of the time profile has important consequences for particle formation rates in the natural environment. Particle nucleation is a non-linear process requiring high concentrations of condensable gases to be localised in "hot-spots" (e.g. Burkholder et al., 2004), and this work suggests that the strongest hotspots are likely to be found over areas of kelp species in the first few minutes after having been exposed by a receding tide.

(iii) $\mathrm{I}_{2}$ emissions were observed when fragments of $L$. digitata thalli were exposed to $90 \mathrm{ppbv}$ of ozone and oligoguluronate (GG) stress. For example, the addition of ozone restarted $\mathrm{I}_{2}$ emissions from a $L$. digitata sample that had largely relaxed following its initial $\mathrm{I}_{2}$ burst on exposure to air. The application of such external stresses produced modest changes in the shape of $\mathrm{I}_{2}$ time profile (typically prolonging the emissions) but did not noticeably increase the average $\mathrm{I}_{2}$ emission rate compared to air-exposure alone. In contrast, Palmer et al. (2005) and Küpper et al. (2008) observed larger $\mathrm{I}_{2}$ emissions for GG stress and at ozone concentrations in excess of those used here. Very large, sustained emissions were however observed from $L$. digitata exposed to the combined stress factors of air $+\mathrm{GG}+90 \mathrm{ppbv}$ of $\mathrm{O}_{3}$.

(iv) Particle formation accompanied the $\mathrm{I}_{2}$ emissions in all L. digitata stress experiments where ozone was present (90 ppbv) together with light, provided that the $\mathrm{I}_{2}$ mixing ratio was above certain threshold levels. The particle number concentrations closely tracked variations in the $\mathrm{I}_{2}$ mixing ratios: a linear relationship was observed at modest $\mathrm{I}_{2}$ mixing ratios, with evidence of a roll-off in particle numbers at high $\mathrm{I}_{2}$ presumably due to coagulation and/or condensational growth of the particles. No significant particle formation was observed without ozone, or in the dark when ozone was present. These observations tally with current understanding of the nucleation mechanism: light is required to photolyse $\mathrm{I}_{2}$ molecules into I atoms which then react with ozone to produce condensable iodine oxides. 
We hesitate to recommend emission factors based on this work because so few replicate observations were performed. Further studies are needed with multiple replicates to generate statistically robust emission rates across sample populations, including investigating how the $\mathrm{I}_{2}$ emission rates of individual species depend on the age and health of the samples, and potentially also on the season of the year (e.g. Ar Gall et al., 2004). However, parameterised versions of the emission rates observed in this work have been "tested" by being used as inputs into the Leigh et al. (2009) model of the emissions, transport and photo-destruction of molecular iodine during the RHaMBLe Roscoff campaign. A main conclusion of this modelling exercise is that the $\mathrm{I}_{2}$ amounts observed at a given location (and thus also the IO and particle concentrations etc arising from atmospheric processing of $I_{2}$ ) depend crucially on the spatial distribution of seaweed species around the measurement site. This is probably also why spectroscopic measurements of $I_{2}$ and the phenomenon of coastal ultra-fine particle nucleation were first identified at Mace Head. L. digitata is abundant around the Mace Head area and the nearest L. digitata beds lie within $120 \mathrm{~m}$ of the shoreline laboratories at the Mace Head Atmospheric Research Station, compared to the kilometre distances at Roscoff.

Acknowledgements. The authors wish to thank staff at the Station Biologique de Roscoff for their logistical support and hospitality during the RHaMBLe project. The Natural Environment Research Council funded the RHaMBLe consortium through several grant awards including NE/D00652X/1 (Leicester University) and NE/D006570/1 (Manchester University).

Edited by: R. von Glasow

\section{References}

Almeida, M., Filipe, S., Humanes, M., Maia, M. F., Melo, R., Severino, N., da Silva, J. A. L., Frausto da Silva, J. J. R., and Wever, R.: Vanadium haloperoxidases from brown algae of the Laminariaceae family, Phytochemistry, 57, 633-642, 2001.

Ar Gall, E., Küpper, F. C., and Kloareg, B.: A survey of iodine content in Laminaria digitata, Bot. Mar., 47, 30-37, 2004.

Bale, C. S. E., Ingham, T., Commane, R., Heard, D. E., and Bloss, W. J.: Novel measurements of atmospheric iodine species by resonance fluorescence, J. Atmos. Chem., 60, 51-70, 2008.

Ball, S. M. and Jones, R. L.: Broadband cavity ring-down spectroscopy, in: "Cavity ring-down spectroscopy: Techniques and applications", edited by: Berden, G. and Engeln, R., Blackwell Publishing Ltd, 2009.

Bitter, M., Ball, S. M., Povey, I. M., and Jones, R. L.: A broadband cavity ringdown spectrometer for in-situ measurements of atmospheric trace gases, Atmos. Chem. Phys., 5, 2547-2560, doi:10.5194/acp-5-2547-2005, 2005.

Bloss, W. J., Lee, J. D., Johnson, G. P., Sommariva, R., Heard, D. E., Saiz-Lopez, A., Plane, J. M. C., McFiggans, G., Coe, H., Flynn, M., Williams, P., Rickard, A. R., and Fleming, Z. L.: Impact of halogen monoxide chemistry on boundary layer $\mathrm{OH}$ and $\mathrm{HO}_{2}$ concentrations at a coastal site, Geophys. Res. Lett., 32, L06814, doi:10.1029/2004GL022084, 2005.

Bloss, W. J. and Ball, S. M.: Iodine chemistry in the coastal marine atmosphere, Bulletin of the Environmental Chemistry Group, Royal Society of Chemistry, ISBN 1758-6224, online available at: http://www.rsc.org/images/ECGBulletinJuly2009_ tcm18-157764.pdf, 2040-1469, 2009.

Burkholder, J. B., Curtius, J., Ravishankara, A. R., and Lovejoy, E. R.: Laboratory studies of the homogeneous nucleation of iodine oxides, Atmos. Chem. Phys., 4, 19-34, doi:10.5194/acp-4-192004, 2004.

Cainey, J. M., Keywood, M., Bigg, E. K., Grose, M. R., Gillett, R. W., and Meyer, M.: Flux chamber study of particle formation from Durvillaea potatorum, Environ. Chem., 4, 151-154, 2007.

Colin, C., Leblanc, C., Michel, G., Wagner, E., Leize-Wagner, E., van Dorsselaer, A., and Potin, P.: Vanadium-dependent iodoperoxidases in Laminaria digitata, a novel biochemical function diverging from brown algal bromoperoxidases, J. Biol. Inorg. Chem., 10, 156-166, 2005.

Cosse, A., Potin, P., and Leblanc, C.: Patterns of gene expression induced by oligoguluronates reveals conserved and environmentspecific defence responses in the brown alga Laminaria digitata, New Phytol., 182, 239-250, 2009.

Davis, D., Crawford, J., Liu, S., McKeen, S., Bandy, A., Thornton, D., Rowland, F., and Blake, D.: Potential impact of iodine on tropospheric levels of ozone and other critical oxidants, J. Geophys. Res.-Atmos., 101, 2135-2147, 1996.

Dixneuf, S., Ruth, A. A., Vaughan, S., Varma, R. M., and Orphal, J.: The time dependence of molecular iodine emission from Laminaria digitata, Atmos. Chem. Phys., 9, 823-829, doi:10.5194/acp-9-823-2009, 2009.

Finley, B. D. and Saltzman, E. S.: Observations of $\mathrm{Cl}_{2}, \mathrm{Br}_{2}$ and $\mathrm{I}_{2}$ in coastal marine air, J. Geophys. Res., 113, D21301, doi:10.1029/2008JD010269, 2008.

Greenblatt, G. D., Orlando, J. J., Burkholder, J. B., and Ravishankara, A. R.: Absorption measurements of oxygen between 330 and 1140 nm, J. Geophys. Res., 95, 18577-18582, 1990.

Hermans, C.: Measurement of absorption cross sections and spectroscopic molecular parameters: $\mathrm{O}_{2}$ and its collision induced absorption, online available at: http://spectrolab.aeronomie.be/o2. htm, last access: 7 December 2009, Belgian Institute for Space Aeronomy, 2008.

Huang, R.-J., Seitz, K., Buxmann, J., Poehler, D., Hornsby, K. E., Carpenter, L. J., Platt, U., and Hoffmann, T.: In situ measurements of molecular iodine in the marine boundary layer: the link to macroalgae and the implications for $\mathrm{O}_{3}, \mathrm{IO}, \mathrm{OIO}$ and $\mathrm{NO}_{\mathrm{x}}$, Atmos. Chem. Phys., 10, 4823-4833, doi:10.5194/acp-10-48232010, 2010.

Jimenez, J. L., Bahreini, R., Cocker III, D. R., Zhuang, H., Varutbangkul, V., Flagan, R. C., Seinfeld, J. H., O’Dowd, C. D., and Hoffmann, T.: New particle formation from photoxidation of diiodomethane $\left(\mathrm{CH}_{2} \mathrm{I}_{2}\right)$, J. Geophys. Res., 108, 4318, doi:10.1029/2002JD002452, 2003.

Kaltsoyannis, N. and Plane, J. M. C.: Quantum chemical calculations on a selection of iodine-containing species (IO, OIO, $\mathrm{INO}_{3}$, $(\mathrm{IO})_{2}, \mathrm{I}_{2} \mathrm{O}_{3}, \mathrm{I}_{2} \mathrm{O}_{4}$ and $\mathrm{I}_{2} \mathrm{O}_{5}$ ) of importance in the atmosphere, Phys. Chem. Chem. Phys., 10, 1723-1733, 2008.

Krenn, B. E., Tromp, M. G., and Wever, R.: The brown alga Ascophyllum nodosum contains two different vanadium bromoperox- 
idases, J. Biol. Chem., 264, 19287-19292, 1989.

Küpper, F. C., Schweigert, N., Ar Gall, E., Legendre, J.-M., Vilter, H., and Kloareg, B.: Iodine uptake in Laminariales involves extracellular, haloperoxidase-mediated oxidation of iodide, Planta, 207, 163-171, 1998.

Küpper, F. C., Carpenter, L. J., McFiggans, G. B., Palmer, C. J., Waite, T. J., Boneberg, E.-M., Woitsch, S., Weiller, M., Abela, R., Grolimund, D., Potin, P., Bulter, A., Luther III, G. W., Kroneck, P. M. H., Meyer-Klaucke, W., and Feiters, M. C.: Iodine accumulation provides kelp with an inorganic antioxidant impacting atmospheric chemistry, P. Natl. Acad. Sci., 105, 69546958, 2008.

Langridge, J. M., Ball, S. M., and Jones, R. L.: A compact broadband cavity enhanced absorption spectrometer for detection of atmospheric $\mathrm{NO}_{2}$ using light emitting diodes, Analyst, 131, 916922, 2006.

Langridge, J. M., Ball, S. M., Shillings, A. J. L., and Jones, R. L.: A broadband absorption spectrometer using light emitting diodes for ultra-sensitive, in situ trace gas detection, Rev. Sci. Instrum., 79, 123110, doi:10.1063/1.3046282, 2008.

Leigh, R. J., Ball, S. M., Whitehead, J., Leblanc, C., Shillings, A. J. L., Mahajan, A. S., Oetjen, H., Dorsey, J. R., Gallagher, M., Jones, R. L., Plane, J. M. C., Potin, P., and McFiggans, G.: Measurements and modelling of molecular iodine emissions, transport and photodestruction in the coastal region around Roscoff, Atmos. Chem. Phys. Discuss., 9, 21165-21198, doi:10.5194/acpd-9-21165-2009, 2009.

Mahajan, A. S., Oetjen, H., Saiz-Lopez, A., Lee, J. D., McFiggans, G. B., and Plane, J. M. C.: Reactive iodine species in a semi-polluted environment, Geophys. Res. Lett., 36, L16803, doi:10.1029/2009GL038018, 2009.

Martin, F., Bacis, R., Churassy, S., and Verges, J.: Laser-induced fluorescence Fourier transform spectroscopy of the $\mathrm{X}^{1} \Sigma_{g}^{+}$state of $\mathrm{I}_{2}$ : Extensive analysis of the $\mathrm{B}^{3} \Pi\left(\mathrm{O}_{u}^{+}\right) \rightarrow \mathrm{X}^{1} \Sigma_{g}^{+}$fluorescence spectrum of ${ }^{127} \mathrm{I}_{2}$, J. Mol. Spectrosc., 116, 71-100, 1986.

Martinelango, P. K., Tian, K., and Dasgupta, P. K.: Perchlorate in seawater: Bioconcentration of iodide and perchlorate by various seaweed species, Anal. Chim. Acta, 567, 100-107, 2006.

McFiggans, G., Coe, H., Burgess, R., Allan, J., Cubison, M., Alfarra, M. R., Saunders, R., Saiz-Lopez, A., Plane, J. M. C., Wevill, D., Carpenter, L., Rickard, A. R., and Monks, P. S.: Direct evidence for coastal iodine particles from Laminaria macroalgae - linkage to emissions of molecular iodine, Atmos. Chem. Phys., 4, 701-713, doi:10.5194/acp-4-701-2004, 2004.

McFiggans, G., Artaxo, P., Baltensperger, U., Coe, H., Facchini, M. C., Feingold, G., Fuzzi, S., Gysel, M., Laaksonen, A., Lohmann, U., Mentel, T. F., Murphy, D. M., O’Dowd, C. D., Snider, J. R., and Weingartner, E.: The effect of physical and chemical aerosol properties on warm cloud droplet activation, Atmos. Chem. Phys., 6, 2593-2649, doi:10.5194/acp-6-2593-2006, 2006.

McFiggans, G., Bale, C. S. E., Ball, S. M., Beams, J. M., et al.: Iodine-mediated coastal particle formation: an overview of the Reactive Halogens in the Marine Boundary Layer (RHaMBLe) Roscoff coastal study, Atmos. Phys. Chem., 10, 2975-2999, doi:10.5194/acp-10-2975-2010, 2010.

O’Dowd, C. D., Jimenez, J. L., Bahreini, R., Flagan, R. C., Seinfeld, J. H., Hameri, K., Pirjola, L., Kulmala, M., Jennings, S. G., and Hoffmann, T.: Marine aerosol formation from biogenic iodine emissions, Nature, 417, 632-636, 2002.

O'Dowd, C. D. and Hoffmann, T.: Coastal new particle formation: A review of the current state-of-the-art, Environ. Chem., 2, 245255, 2005.

Pacios, L. F., and Galvez, O.: Active site, catalytic site, and iodination reactions of vanadium iodoperoxidase: a computational study, J. Chem. Theory Comput., 6, 1738-1752, 2010.

Palmer, C. J., Anders, T. L., Carpenter, L. J., Küpper, F. C., and McFiggans, G. B.: Iodine and halocarbon response of Laminaria digitata to oxidative stress and links to atmospheric new particle formation, Environ. Chem., 2, 282-290, 2005.

Peters, C., Pechtl, S., Stutz, J., Hebestreit, K., Hönninger, G., Heumann, K. G., Schwarz, A., Winterlik, J., and Platt, U.: Reactive and organic halogen species in three different European coastal environments, Atmos. Chem. Phys., 5, 3357-3375, doi:10.5194/acp-5-3357-2005, 2005.

Pirjola, L., O’Dowd, C. D., Yoon, Y. J., and Sellegri, K.: Modelling iodine particle formation and growth from seaweed in a chamber, Environ. Chem., 2, 271-281, 2005.

Rothman, L. S., Jacquemart, D., Barbe, A., Benner, D. C., Birk, M., Brown, L. R., Carleer, M. R., Chackerian Jr, C., Chance, K., Coudert, L. H., Dana, V., Devi, V. M., Flaud, J.-M., Gamache, R. R., Goldman, A., Hartmann, J.-M., Jucks, K. W., Maki, A. G., Mandin, J.-Y., Massie, S. T., Orphal, J., Perrin, A., Rinsland, C. P., Smith, M. A. H., Tennyson, J., Tolchenov, R. N., Toth, R. A., Vander Auwera, J., Varanasi, P., and Wagner, G.: The HIRTAN 2004 molecular spectroscopic database, J. Quant. Spectrosc. Rad. Transfer, 96, 139-204, 2005.

Rousseau, F., Burrowes, R., Peters, A. F., Kuhlenkamp, R., and de Reviers, B.: A comprehensive phylogeny of the Phaeophyceae based on nrDNA sequences resolves the earliest divergences, C. R. Acad. Sci., 324, 305-319, 2001,

Saiz-Lopez, A. and Plane, J. M. C.: Novel iodine chemistry in the marine boundary layer, Geophys. Res. Lett., 31, L04112, doi:10.1029/2003GL019215, 2004.

Saiz-Lopez, A., Saunders, R. W., Joseph, D. M., Ashworth, S. H., and Plane, J. M. C.: Absolute absorption cross-section and photolysis rate of $\mathrm{I}_{2}$, Atmos. Chem. Phys., 4, 1443-1450, doi:10.5194/acp-4-1443-2004, 2004.

Saiz-Lopez, A., Plane, J. M. C., McFiggans, G., Williams, P. I., Ball, S. M., Bitter, M., Jones, R. L., Hongwei, C., and Hoffmann, T.: Modelling molecular iodine emissions in a coastal marine environment: the link to new particle formation, Atmos. Chem. Phys., 6, 883-895, doi:10.5194/acp-6-883-2006, 2006.

Sellegri, K., Yoon, Y. J., Jennings, S. G., O’Dowd, C. D., Pirjola, L., Cautenet, S., Chen, H., and Hoffmann, T.: Quantification of coastal new ultra-fine particles formation from in situ and chamber measurements during the BIOFLUX campaign, Environ. Chem., 2, 260-270, 2005.

Seitz, K.: The spatial distribution of reactive halogen species at the Irish west coast, PhD dissertation, University of Heidelberg, Germany, 2009.

Sneep, M. and Ubachs, W.: Direct measurement of the Rayleigh scattering cross section in various gases, J. Quant. Spectrosc. Rad. Transfer, 92, 293-310, 2005.

Teas, J., Pino, S., Critchley, A., and Braverman, L. E.: Variability of iodine content in common commercially available edible seaweeds, Thyroid, 14, 836-841, 2004.

Verhaeghe, E. F., Fraysse, A., Guerquin-Kern, J.-L., Wu, T.-D., 
Devès, G., Mioskowski, C., Leblanc, C., Ortega, R., Ambroise, Y., and Potin, P.: Microchemical imagining of iodine distribution in the brown alga Laminaria digitata suggests a new mechanism for its accumulation, J. Biol. Inorg. Chem., 13, 257-269, 2008.

Von Glasow, R. and Crutzen, P. J.: Tropospheric halogen chemistry, edited by: Holland, H. D. and Turekian, K. K., Treatise on Geochemistry, 1(4.02), 1-67, 2007.

Vuollekoski, H., Kerminen, V.-M., Anttila, T., Sihto, S.-L., Vana, M., Ehn, M., Korhonen, H., McFiggans, G., O’Dowd, C. D., and Kulmala, M.: Iodine dioxide nucleation simulations in coastal and remote marine environments, J. Geophys. Res., 114, D02206, doi:10:10.29/2008JD010713, 2009.

Wada, R., Beames, J. M., and Orr-Ewing, A. J.: Measurement of IO radical concentrations in the marine boundary layer using a cavity ring-down spectrometer, J. Atmos. Chem., 58, 69-87, 2007.
Western, C. M.: PGOPHER: a program for simulating rotational structure, University of Bristol (UK), http://pgopher.chm.bris.ac. uk, last access: 7 December 2009, 2009.

Whalley, L. K., Furneaux, K. L., Gravestock, T., Atkinson, H. M., Bale, C. S. E., Ingham, T., Bloss, W. J., and Heard, D. E.: Detection of iodine monoxide radicals in the marine boundary layer using laser induced fluorescence spectroscopy, J. Atmos. Chem., 58, 19-39, 2007.

Whitehead, J. D., McFiggans, G. B., Gallagher, M. W., and Flynn, M. J.; Direct linkage between tidally driven coastal ozone deposition fluxes, particle emission fluxes, and subsequent CCN formation, Geophys. Res. Lett., 36, L04806, doi:10.1029/2008GL035969, 2009. 